University of Louisville

ThinkIR: The University of Louisville's Institutional Repository

Electronic Theses and Dissertations

8-2017

\title{
Mechanism investigation of pseudouridine synthases TruB and RluA with RNA containing 5-fluorouridine and 4-thiouridine.
}

Uyen T. Duong

University of Louisville

Follow this and additional works at: https://ir.library.louisville.edu/etd

Part of the Biochemistry Commons

\section{Recommended Citation}

Duong, Uyen T., "Mechanism investigation of pseudouridine synthases TruB and RluA with RNA containing 5-fluorouridine and 4-thiouridine." (2017). Electronic Theses and Dissertations. Paper 2781.

https://doi.org/10.18297/etd/2781

This Master's Thesis is brought to you for free and open access by ThinkIR: The University of Louisville's Institutional Repository. It has been accepted for inclusion in Electronic Theses and Dissertations by an authorized administrator of ThinkIR: The University of Louisville's Institutional Repository. This title appears here courtesy of the author, who has retained all other copyrights. For more information, please contact thinkir@louisville.edu. 
MECHANISM INVESTIGATION OF PSEUDOURIDINE SYNTHASES TruB AND

RluA WITH RNA CONTAINING 5-FLUOROURIDINE AND 4-THIOURIDINE

By

\author{
Uyen T. Duong \\ M.S., Chosun University, 2010 \\ B.S., Vietnam National University, 2008
}

\begin{abstract}
A Thesis
Submitted to the Faculty of the

College of Arts and Sciences of the University of Louisville in Partial Fulfillment of the Requirements for the Degree of
\end{abstract}

Master of Science in Chemistry

Department of Chemistry University of Louisville

Louisville, Kentucky

August, 2017 

MECHANISM INVESTIGATION OF PSEUDOURIDINE SYNTHASES TruB AND RluA WITH RNA CONTAINING 5-FLUOROURIDINE AND 4-THIOURIDINE

By

Uyen T. Duong

M.S., Chosun University, 2010

B.S., Vietnam National University, 2008

A Thesis Approved on

July 3, 2017

By the Following Thesis Committee:

Thesis Director

Professor Eugene G. Mueller

Professor Ying Li

Professor Muriel C. Maurer

Professor David J. Schultz 


\section{DEDICATION}

This thesis is dedicated to

My parents Duong Hong Hai and Nghiem Thi Thai,

Brother Duong Hong Quan, sister Duong Thi Kieu Oanh,

beloved husband Tu Quang Nguyen, and my lovely

daughters Sophia Nguyen and Ruby Nguyen 


\section{ACKNOWLEDGEMENTS}

Foremost, I would like to thank my advisor Professor Eugene Mueller for giving me an opportunity to be a part of his research group. His insightful guidance allowed me to think critically and motivated me to develop throughout 2.5 years at University of Louisville. I extremely appreciate his strong support and endless encouragement. I also had the great opportunity of taking his course in Biochemistry during my first year at the graduate school. His class provided me valuable knowledge in the field of enzymology that I hope to apply through my career. He is the best mentor and teacher I have ever known. Without his helpful guidance, I would never have completed this thesis.

I would like to acknowledge Professor Ying Li, Professor Muriel C. Maurer, Professor David J. Schultz for serving as my committee members. I appreciate their feedback and suggestions that have greatly improved this thesis.

I thank my previous lab mates, Dr. Govardhan reddy Veerareddygari, who was always willing to teach me everything when I first joined the lab, Dr. Kelly Sullivan for her help with troubleshooting and discussions. I would like to thank my current lab Austin Gibbs for sharing his knowledge in Biochemistry and for his friendly behavior.

I would like to thank my friends who was willing to talked and discussed every time I needed. I was not alone since I was shared by Paige Monsen, Faye Carvajal, Ram Hona, Abdullah Mamun, Nour Jamhawi, and Biyun Shi. 
Last but not least, I am grateful to my parents, my brother, my sister and my husband for always being with me and loving me. I also owe great deal to my kids Sophia and Ruby for being with me, my life cannot be more beautiful than seeing you every day. 


\begin{abstract}
MECHANISM INVESTIGATION OF PSEUDOURIDINE SYNTHASES TruB AND RluA WITH RNA CONTAINING 5-FLUOROURIDINE AND 4-THIOURIDINE
\end{abstract}

\author{
Uyen T Duong
}

July 3,2017

Pseudouridine synthases ( $\Psi$ synthases) are the enzymes that catalyze the isomerization of uridine $(\mathrm{U})$ to pseudouridine $(\Psi)$, which is the most prevalent posttranscriptional modification of RNA. The $\Psi$ synthases fall into six different families that share no significant global sequence similarity; however, they all involve a conserved aspartic acid residue which is absolutely essential for activity.

Tyrosine is a conserved residue in the active site in five of the six families of $\Psi$ synthases (phenylalanine in the TruD family) and was hypothesized as the general base for the isomerization reaction. To confirm the function of Tyr-96, Y96F RluA was assayed with both ASL and $\left[\mathrm{F}^{5} \mathrm{U}\right] \mathrm{ASL}$. $\mathrm{U}$ is converted to $\Psi$ and $\mathrm{F}^{5} \mathrm{U}$ to $\mathrm{F}^{5} \mathrm{U}$ products. These results argue against the role of Tyr serving as general base. However, the slow rates of reactions and higher concentration of $\mathrm{Y} 96 \mathrm{~F}$ RluA needed for any reaction indicates that Tyr-96 does facilitates at least one step of the reaction.

The major product of $\mathrm{F}^{5} \mathrm{U}$ from the action of $\Psi$ synthases is a ribo isomer whereas the minor product is arabino, and its generation requires epimerization at $\mathrm{C}^{\prime}$. The 
deprotonation at $\mathrm{C}^{\prime}$ can be achieved by the conserved Asp or $\mathrm{O}^{2}$. To test if $\mathrm{O}^{2}$ is the general base, the isomerized $U$ was replaced by 4 -thiouridine $\left(s^{4} U\right)$. As an essential first step, RNA containing $s^{4} U$ needs to be verified as a good substrate for $\Psi$ synthases, so RluA and TruB were incubated with $\left[\mathrm{s}^{4} \mathrm{U}\right] \mathrm{RNA}$. Intact $\left[\mathrm{s}^{4} \mathrm{U}\right] \mathrm{RNA}$ shifted to later and shorter retention times after incubation with RluA and TruB, respectively. Traces of the digestion products of $\left[\mathrm{s}^{4} \mathrm{U}\right] \mathrm{RNA}$ after incubation with the two enzymes also showed the new peaks that absorbed more strongly at $330 \mathrm{~nm}$ than $260 \mathrm{~nm}$. These results indicate that $\left[\mathrm{s}^{4} U\right] R N A$ can be handled as a substrate. 


\section{TABLE OF CONTENTS}

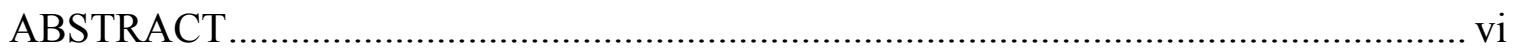

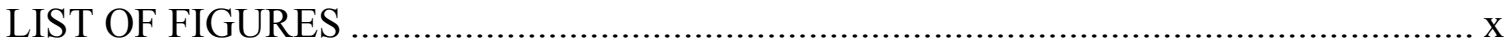

CHAPTER I PSEUDOURIDINE AND THE PSEUDOURIDINE SYNTHASES ........... 1

1.1 Physiological significance of pseudouridine .................................................. 2

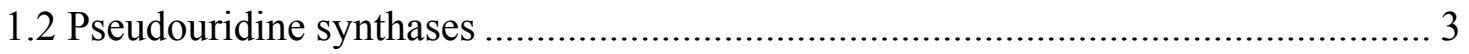

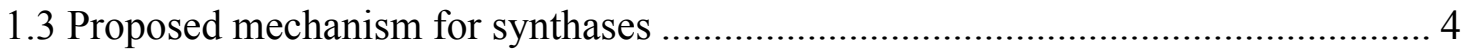

CHAPTER II MECHANISTIC INVESTIGATION OF Y96F RluA USING ASL AND

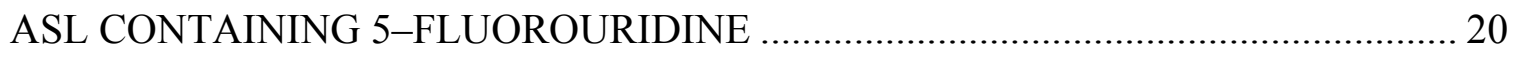

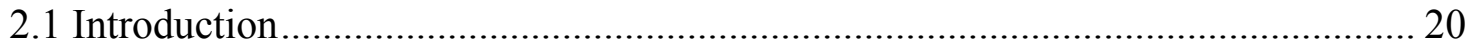

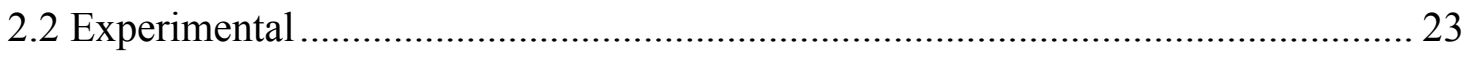

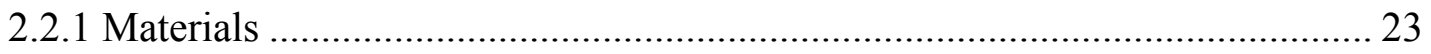

2.2.2 Overexpression and Purification of Y96F RluA....................................... 23

2.2.3 Deprotection and Purification of 2'-ACE RNA Oligonucleotides................... 25

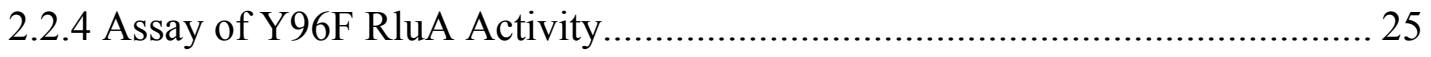

2.2.5 Formation of the Adduct between Y96F RluA and [F $\left.{ }^{5} \mathrm{U}\right] \mathrm{ASL}$......................... 27

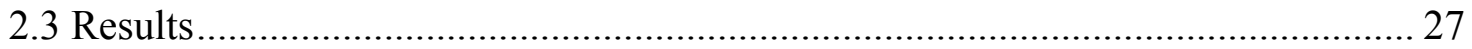

2.3.1 Overexpression and Purification of Y96F RluA........................................ 27

2.3.2 Y96F RluA isomerizes uridine and $\mathrm{F}^{5} \mathrm{U}$ in stem-loop substrate..................... 29

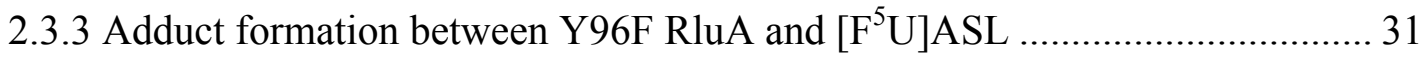

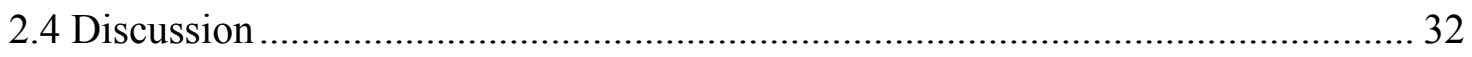

CHAPTER III MECHANISTIC INVESTIGATION OF RluA and TruB USING RNA

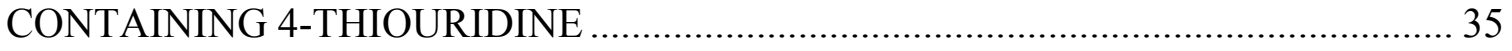

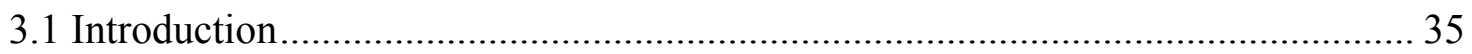




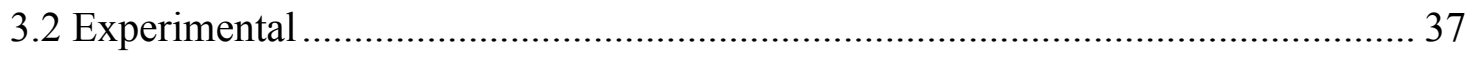

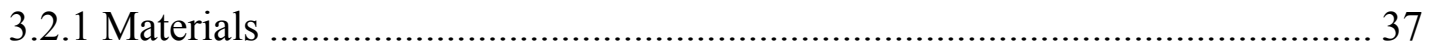

3.2.2 Overexpression and purification of wild-type RluA and TruB ..................... 38

3.2.3 Deprotection and Purification of 2'-ACE RNA Oligonucleotides................... 38

3.2.4 Assay of RluA and ASL containing 4-thiouridine ....................................... 38

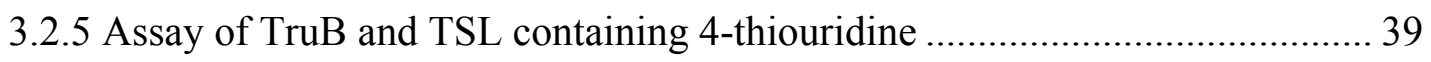

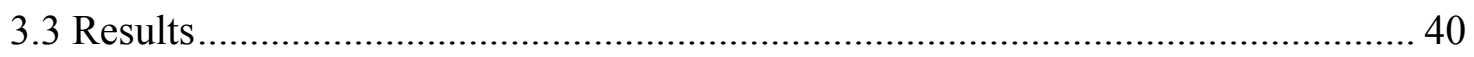

3.3.1 Assay of RluA and ASL containing 4-thiouridine .................................... 40

3.3.2 Assay of TruB and TSL containing 4-thiouridine ...................................... 42

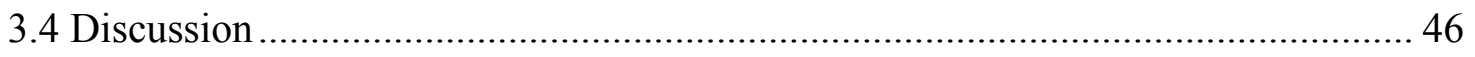

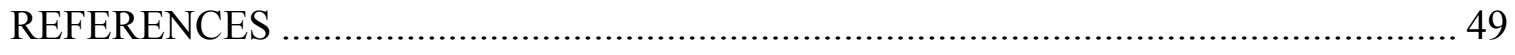

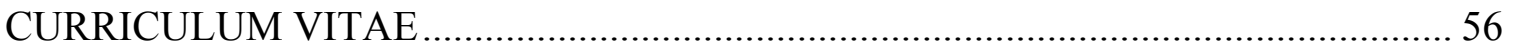




\section{LIST OF FIGURES}

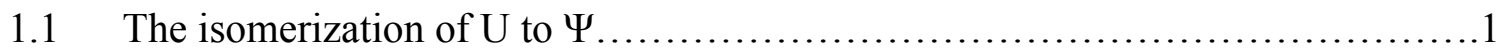

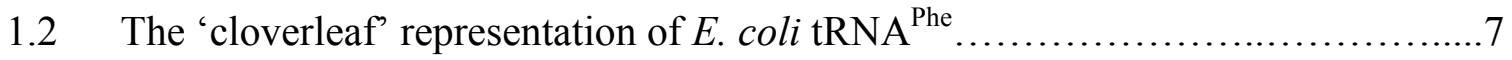

1.3 The "Michael mechanism" for $\Psi$ synthases.................................

1.4 The "acylal mechanism" for $\Psi$ synthases..................................

1.5A 5-fluorouracil...................................................... 10

1.5B 5-fluorouridine................................................... 10

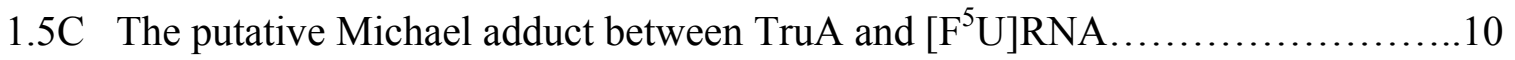

$1.6{ }^{18} \mathrm{O}$ labeling scheme....................................................

1.7 A consistent scheme for the handling of $F^{5} U$ in RNA by different $\Psi$ synthase....12

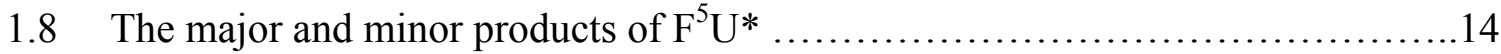

1.9 The acylal mechanism recast to account for the arabino product.................14

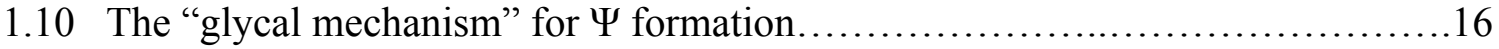

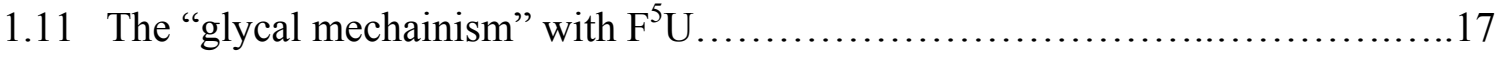

1.12 A scheme proposed by the Mueller group................................ 18

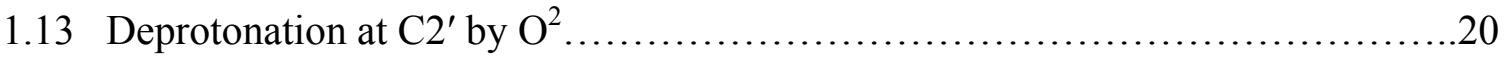

2.1 Mechanism proposed by Phannachet et al for the $\Psi$ synthases...................23

2.2 The crystal structural between Tyr-140 and the pyrimidine ring................24 
2.3 SDS-PAGE analysis of the overexpression and purification of Y96F RluA........30

2.4 Time course for the conversion of ASL upon incubation with Y96F RluA.........31

2.5 HPLC analysis of $\left[\mathrm{F}^{5} \mathrm{U}\right] \mathrm{ASL}$ after incubation with Y96F RluA....................

2.6 Digestion of $\left[\mathrm{F}^{5} \mathrm{U}\right] \mathrm{ASL}$ after incubated with Y96F RluA.......................

2.7 SDS-PAGE analysis of the formation of the adduct......................... 34

3.1 HPLC analysis of $\left[\mathrm{s}^{4} \mathrm{U}\right] \mathrm{ASL}$ before and after incubation with RluA............42

3.2 HPLC analysis of the nucleosides resulting from digestion of $\left[\mathrm{s}^{4} \mathrm{U}\right] \mathrm{ASL} \ldots \ldots . . .43$

3.3 HPLC analysis of $\left[\mathrm{s}^{4} \mathrm{U}\right] \mathrm{TSL}$ before and after incubation with TruB .............44

3.4 HPLC analysis of the nucleosides resulting from digestion of $\left[\mathrm{s}^{4} \mathrm{U}\right] \mathrm{TSL} \ldots \ldots \ldots . .45$

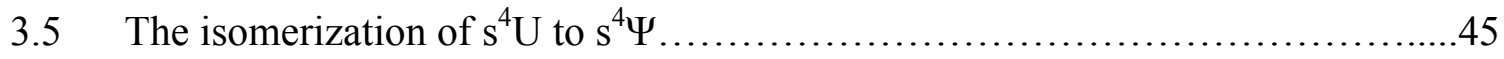

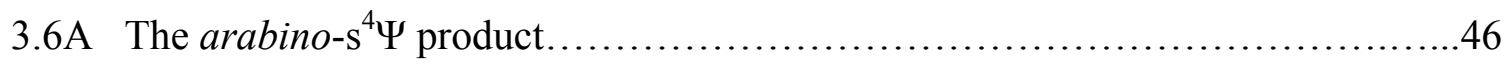

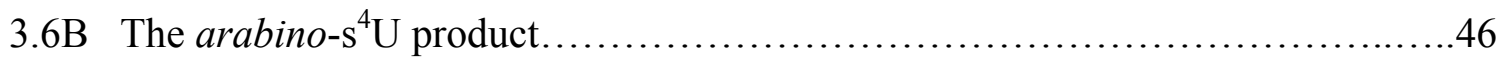

3.7A The ribo- $\mathrm{s}^{4} \Psi$ product from the action of RluA............................46

3.7B Dinucleotide product from the action of TruB ............................46

3.8 The spectra of new peaks from the action of RluA.........................47

3.9 The spectra of new peaks from the action of TruB $\ldots \ldots \ldots \ldots \ldots \ldots \ldots \ldots \ldots \ldots \ldots \ldots$ 


\section{CHAPTER I}

\section{PSEUDOURIDINE AND THE PSEUDOURIDINE SYNTHASES}

Pseudouridine ( $\Psi)$, the C-glycoside isomer of uridine (U) is the most common post-transcriptional modification of RNA [1, 2]. $\Psi$ was discovered in 1951 and is also known as the 'fifth nucleotide' in RNA [1]. $\Psi$ has been found in every species examined and in all classes of RNA [3, 4]. Pseudouridine synthases ( $\Psi$ synthases) are the enzymes responsible for this site-specific isomerization of $U$ to $\Psi$.
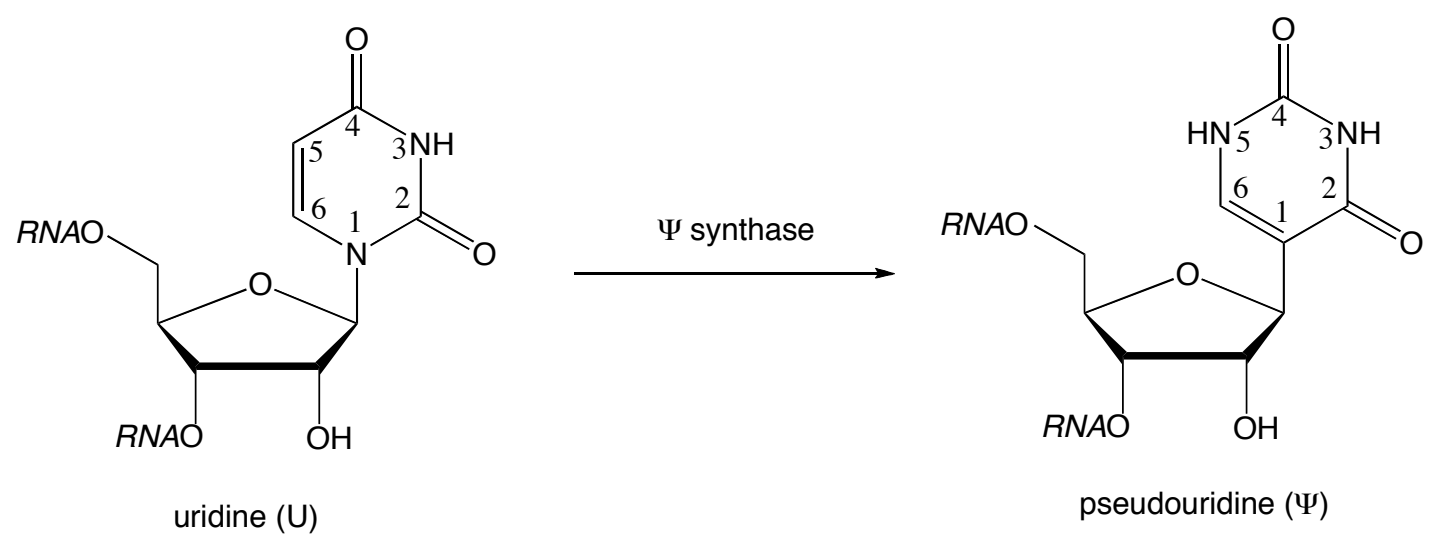

Figure 1.1: The isomerization of $U$ to $\Psi$ 


\subsection{Physiological significance of pseudouridine}

The conversion of $U$ to $\Psi$ occurs in all three domains of life and is the most prevalent post-transcriptional modification [1]; however, the reason for this isomerization and the importance of $\Psi$ at many positions in diverse RNAs have remained poorly understood. A speculative role for $\Psi$ was based on its distinctive physical and chemical properties in comparison with $\mathrm{U}$. The $\mathrm{C}$ glycosidic bond in $\Psi$ enhances rotational freedom as compared to the $\mathrm{N}$ glycosidic bond in $\mathrm{U}$; therefore, $\Psi$ was anticipated to exhibit greater conformational flexibility than $\mathrm{U}$ [5]. Also, the N1-H in $\Psi$ can act as an additional hydrogen bond donor, suggesting that $\Psi$ might impart structural rigidity in RNA. This conclusion has been confirmed by nuclear magnetic resonance [6], CD spectroscopy [7], and molecular dynamics simulations [8]. Furthermore, $\Psi$ enhances local RNA stacking in both single and duplex-stranded, which has been proposed to be the most important contribution of $\Psi$ to the stabilization of RNA structure $[3,6,7,9]$.

The ubiquity of $\Psi$ in all forms of RNA emphasizes its physiological importance. Lack of $\Psi$ at position 1911, 1915, and 1917 of 23S rRNA in Escherichia coli (E. coli) causes severe growth retardation [10-12]. In eukaryotes, $\Psi$ is localized in the region of interaction between $\mathrm{U} 2$ snRNA and pre-mRNA. Absence of $\Psi$ in this position affects the production of mature transcripts by impairing the splicing activity of pre-mRNA [13].

The X-linked form of the human disease dyskeratosis congenita results from a mutation or deletion in the gene dyskerin, an ortholog of the $\Psi$ synthase-encoding Cbf5 gene. Patients with this disease have defects in highly regenerative tissues, such as skin and bone marrow, and chromosomal instability [14-16]. Cells of individuals with this disorder show reduced amounts of telomerase RNA and thus decreased telomerase 
activity with resulting difficulty in maintaining telomere length [14-16]. The lack of $\Psi$ residues and the reduced telomerase activity may be responsible for dyskeratosis congenita.

\subsection{Pseudouridine synthases}

The pseudouridine synthases catalyze the isomerization of $U$ to $\Psi$ at specific positions in certain RNAs. Based on sequence data and structural analysis, the $\Psi$ synthases fall into six different families that share no significant global sequence similarity [17-20] and are named after the first cloned member: TruA [21], TruB [22], RluA [23], RsuA [24], TruD [19], and Pus10 [25]; the first five are from E. coli, and Pus10 is found only in archaea and eukaryotes. Crystal structures from representative members of each family show that they share a common fold with a core $\beta$-sheet along with several conserved active site amino acid residues, so they likely share a common mechanism. The active site of all six families shows an absolutely conserved aspartic acid residue Asp, which was shown to be critical for enzyme activity and proposed to act as a nucleophile in the isomerization reaction $[11,12,26,27]$. In cocrystal structures of several $\Psi$ synthases with RNA, the conserved Asp is located in the same structural position [28].

The work in this thesis focuses on the E. coli $\Psi$ synthases RluA and TruB. RluA (ribosomal large subunit pse $\underline{u}$ douridine synthases) is responsible for the isomerization of U746 in 23S rRNA and U32 in the anticodon stem-loop (ASL) of fives tRNA [19, 2124]. TruB is responsible for the pseudouridylation of U55 in the $\underline{\mathbf{T}}$-arm $\underline{\mathbf{s}}$ tem loop (TSL) in tRNAs [22]. Mueller and co-workers have reported the kinetic parameters of RluA with ASL and full-length tRNA. The value of $k_{\text {cat }}$ with ASL is only 1.5 -fold lower than 
the value with full-length tRNA, and the $K_{\mathrm{m}}$ value is 2.9 -fold higher than with tRNA, indicating that ASL is only a very slightly poorer substrate than full-length tRNA [29]. Similar results were obtained by Santi and co-workers for TruB in comparison of fulllength tRNA and the 17-mer corresponding to yeast TSL [30].

\subsection{Proposed mechanism for synthases}

Two general mechanisms have been proposed for the $\Psi$ synthases. The first was the "Michael mechanism" (Figure 1.3). In this mechanism, the conserved Asp acting as a nucleophile attacks C6 of the pyrimidine ring to form a covalent adduct (a Michael adduct). Following cleavage of the $\mathrm{N}$-glycosidic bond and rotation $180^{\circ}$ around the new bond to the conserved Asp, reattachment at C5 forms the new C-glycosidic bond. The conserved Asp departs as leaving group, and deprotonation at C5 generates $\Psi$.

The second mechanism is the "acylal mechanism" (Figure 1.4), which involves nucleophilic attack by the conserved Asp on $\mathrm{Cl}^{\prime}$ of the ribose ring either through a concerted or step-wise process to form an acylal intermediate. After N-glycosidic bond breakage, the uracilate ion is free to rotate $180^{\circ}$, moving $\mathrm{C} 5$ close to $\mathrm{C} 1^{\prime}$ for $\mathrm{C}$-glycosidic bond formation with the conserved Asp as leaving group. The subsequent deprotonation of C5 by the conserved Asp yields $\Psi$.

5-Fluorouridine $\left(\boldsymbol{F}^{5} \boldsymbol{U}\right)$. 5-Fluorouracil $\left(\mathrm{F}^{5} \mathrm{Ura}\right)$ has been known as a potent anticancer drug for over 60 years. It is widely used in the treatment of various type of cancers, particularly for colorectal and testicular cancers [31]. However, the mechanisms by which $\mathrm{F}^{5} \mathrm{Ura}$ causes cell death and tumours become resistant to $\mathrm{F}^{5}$ Ura remains unclear, although the action of $F^{5} U r a$ involves its conversion to 5-fluorouridine $\left(F^{5} U\right)$. Samuelsson demonstrated that $\mathrm{F}^{5} \mathrm{U}$ inhibits the post-transcriptional conversion of uridine 
to pseudouridine in RNA species and that RNAs containing $\mathrm{F}^{5} \mathrm{U}$ form stable complexes with $\Psi$ synthases [32]. $\mathrm{F}^{5} \mathrm{U}$ is also converted to several intracellular active metabolites such as 5-fluorodeoxyuridine monophosphate ( $\left.\mathrm{F}^{5} \mathrm{dUMP}\right)$, which acts as an inhibitor of thymidylate synthase and thus blocks the sole de novo source of dTTP, which is necessary for DNA replication and repair [31,33]. To examine the mechanism of the $\Psi$ synthases, RNA containing $\mathrm{F}^{5} \mathrm{U}$ ([ $\left.\left.\mathrm{F}^{5} \mathrm{U}\right] \mathrm{RNA}\right)$ was used as a mechanistic probe (Figure 1.5B).

When the $\Psi$ synthase TruA was incubated with $\left[\mathrm{F}^{5} \mathrm{U}\right] \mathrm{tRNA}$, TruA was irreversibly inhibited and formed a covalent adduct between protein and RNA (Figure 1.5C), as judged by denaturing gels [30]. After heat disruption of the adduct, a hydrated product of $\mathrm{F}^{5} \mathrm{U}$ was observed, which was reasonably ascribed to ester hydrolysis of the Michael adduct and thus taken to support the Michael mechanism (Figure 1.3) [34]. However, a noncovalent complex was observed in cocrystals of TruB and $\left[\mathrm{F}^{5} \mathrm{U}\right] \mathrm{TSL}$, but the product of $\mathrm{F}^{5} \mathrm{U}$ was hydrated and also rearranged to the C-glycoside isomer [35]. Based on these observations, Hoang and Ferré-D'Amaré concluded that TruB follows the Michael mechanism and ascribed the absence of a covalent adduct to the slow ester hydrolysis of the Michael adduct during crystal growth and data acquisition [35]. A similar set of experiments with the $\Psi$ synthase RluA revealed that it is also irreversibly inhibited and forms an adduct with $\left[\mathrm{F}^{5} \mathrm{U}\right] \mathrm{ASL}$, similarly to TruA when incubated with [ $\left.\mathrm{F}^{5} \mathrm{U}\right] \mathrm{tRNA}[36]$.

To determine if the products form by ester hydrolysis or direct hydration (Figure 1.6), reactions of [ $\left.\mathrm{F}^{5} \mathrm{U}\right] \mathrm{RNA}$ and TruB [37], RluA [29], and TruA [38] were run in buffer containing $50 \%\left[{ }^{18} \mathrm{O}\right]$ water. In all cases, ${ }^{18} \mathrm{O}$ label ends up in RNA rather than in 
the conserved Asp. These results eliminated ester hydrolysis of the Michael adduct; instead, a water molecular adds directly to the pyrimidine ring. Based on these observations, Mueller and co-workers proposed a scheme to account for the handling of $\mathrm{F}^{5} \mathrm{U}$, in which all $\Psi$ synthases proceeds through either the Michael or acylal mechanisms to rearranged $F^{5} U$ (Figure 1.7). With TruB, the conserved Asp does not form a stable covalent adduct, and the rearranged $F^{5} U$ is spontaneous hydrated when released into solution. In other $\Psi$ synthases (such as RluA and TruA), the conserved Asp can reach C6 to form a covalent adduct between the conserved Asp and $\left[F^{5} U\right] R N A$, which undergoes elimination (rather than ester hydrolysis) to generate rearranged $F^{5} U$ upon heating, followed by spontaneous hydration in solution [29, 38].

Studies by Spedaliere and Mueller proved that $\left[\mathrm{F}^{5} \mathrm{U}\right] \mathrm{TSL}$ neither inhibits nor forms a stable adduct with TruB; in fact, TruB converts $F^{5} U$ into its rearranged and hydrated C-glycoside isomer in a time frame similar to the natural conversion of $\mathrm{U}$ to $\Psi$ [36]. Furthermore, HPLC analysis of the nucleotides resulting from treatment with S1 nuclease and alkaline phosphatase of reacted $\left[\mathrm{F}^{5} \mathrm{U}\right] \mathrm{TSL}$ showed two more polar products of $F^{5} \mathrm{U}$ in a ratio of $\sim 3: 1$ [36]. MALDI-MS analysis confirmed that $\mathrm{F}^{5} \mathrm{U}$ became hydrated after incubation with TruB, consistent with products seen in the cocrystal. NMR experiments revealed that both products of $F^{5} U$ were dinucleotides with the cytidine residue that follow $F^{5} U$ in $\left[F^{5} U\right] T S L$, and an identical result was obtained from the action of TruA on [F ${ }^{5} \mathrm{U}$ RNA [38]. However, HPLC analysis of the RluA products showed a single peak with different retention time than either TruB product [29]. 


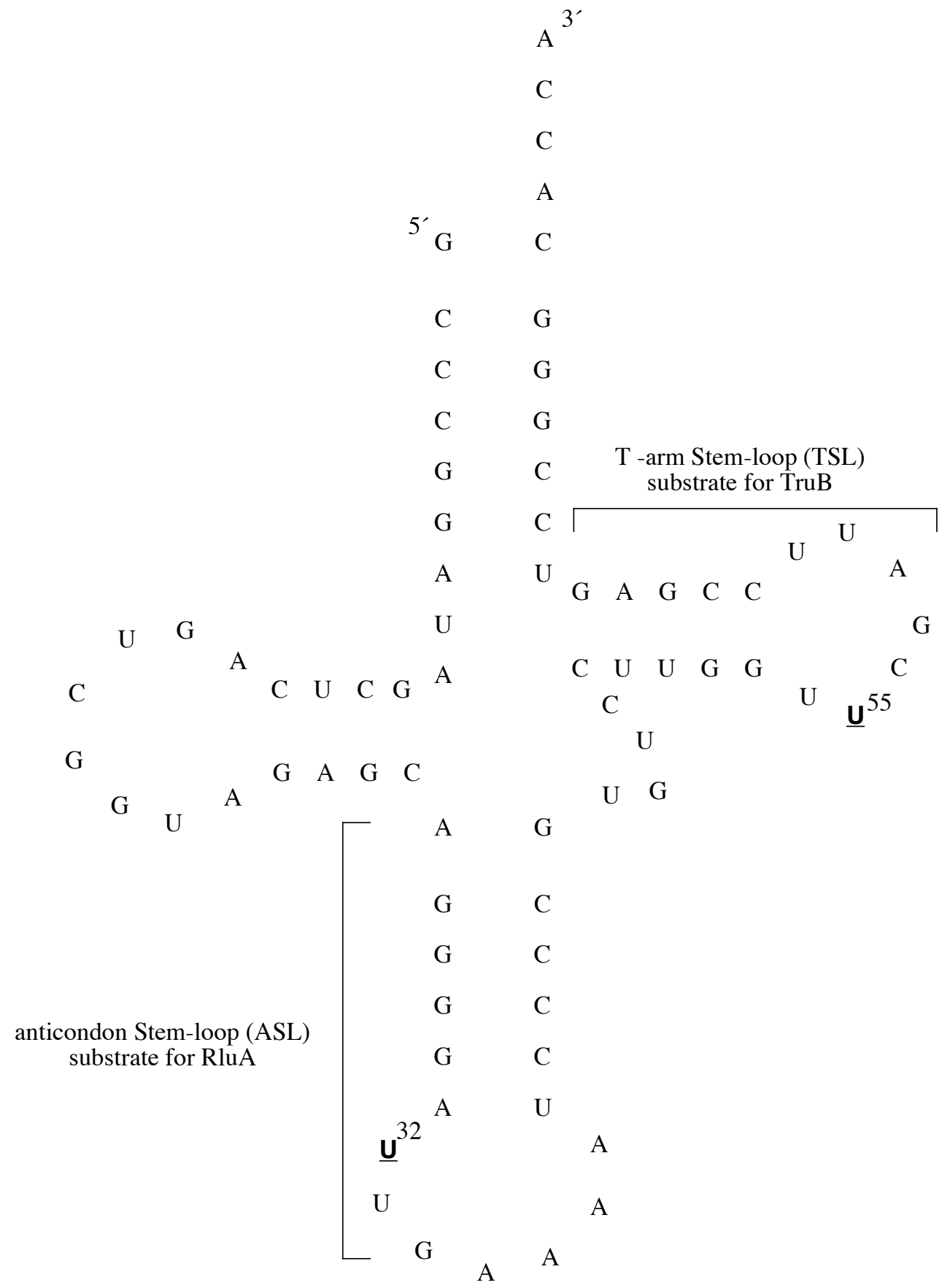

Figure 1.2: The 'cloverleaf' representation of $E$. coli $\mathrm{tRNA}^{\mathrm{Phe}}$. The anticodon $\underline{\text { stem }}$ loop (ASL) is the substrate for RluA, and T-arm stem loop (TSL) is the substrate for TruB, which isomerizes U32 and U55 (underlined), respectively. 


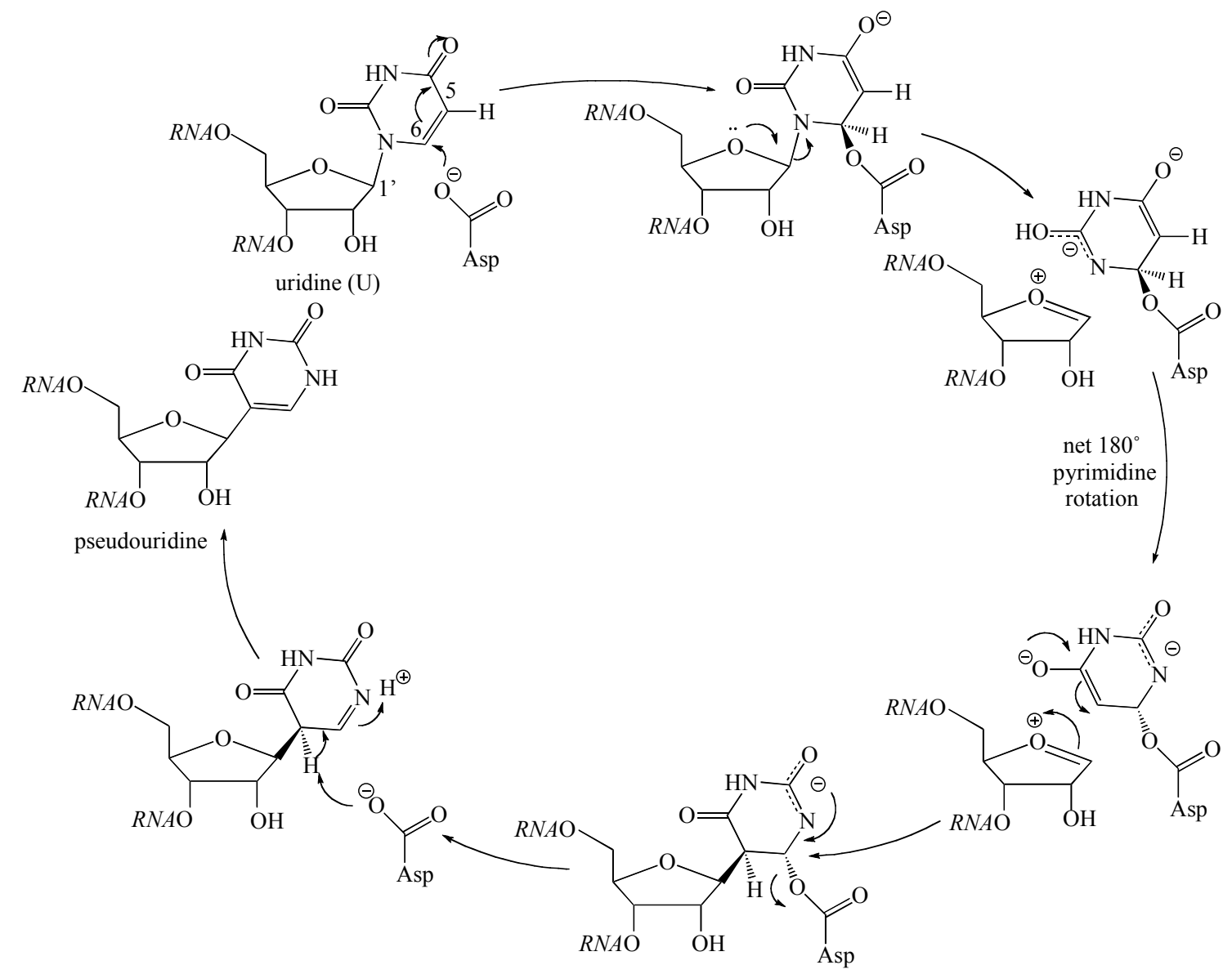

Figure 1.3: The proposed "Michael mechanism" for $\Psi$ synthases. The conserved Asp nucleophilically attacks C6 of the pyrimidine ring to form a covalent adduct (a Michael addition). N-glycosidic bond cleavage occurs, and the pyrimidine ring rotates $180^{\circ}$ around the bond to the conserved Asp. Reattachment at C5 forms the C-glycosidic bond, followed by the elimination of Asp and deprotonation to complete the isomerization. 


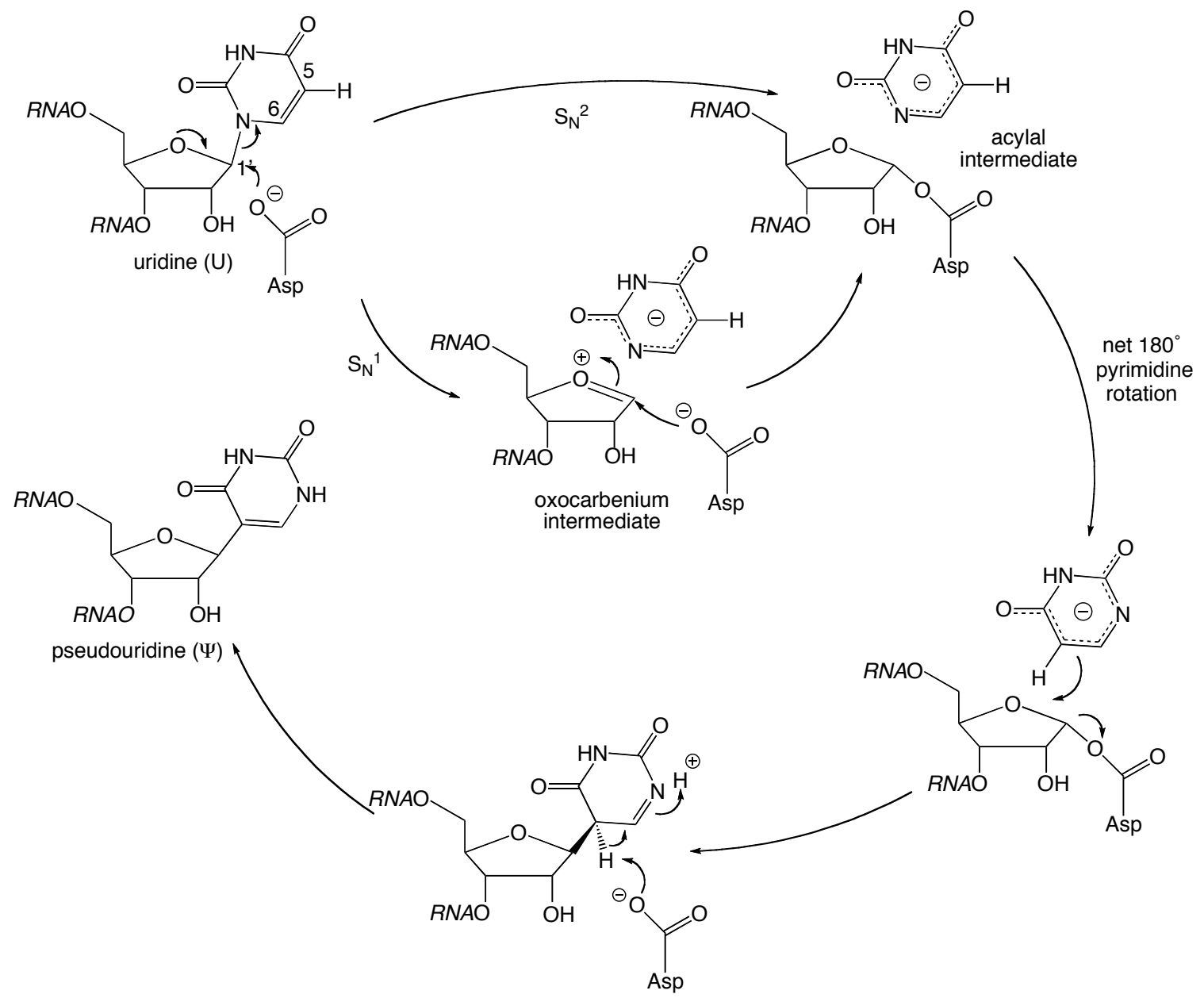

Figure 1.4: The proposed "acylal mechanism" for $\Psi$ synthases. The nucleophilic attack by the conserved Asp on C1' of the ribose ring proceeds through either a concerted or step-wise process to form an acylal intermediate. After N-glycosidic bond breakage, the uracilate ion is free to rotate $180^{\circ}$, bringing $\mathrm{C} 5$ close to $\mathrm{C} 1^{\prime}$ to form the C-glycosidic bond. Deprotonation by the conserved Asp yields $\Psi$. 
A<smiles>O=c1[nH]cc(F)c(=O)[nH]1</smiles>

B

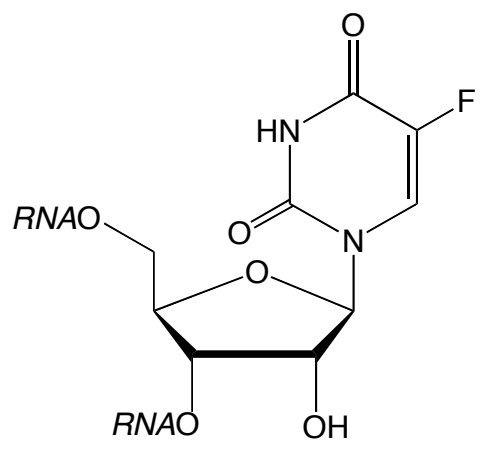

C

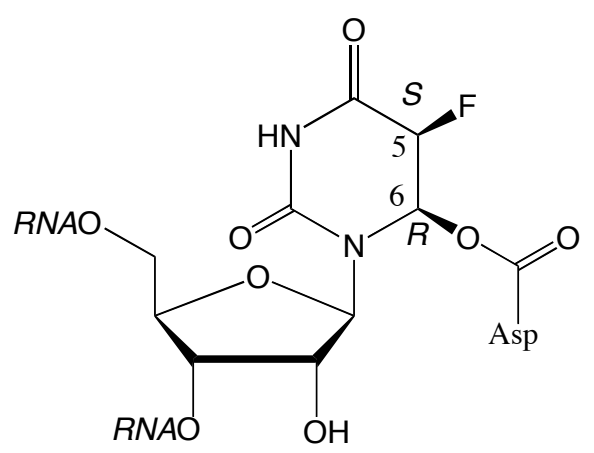

Figure 1.5: A, 5-fluorouracil. B, 5-fluorouridine. C, The putative Michael adduct between TruA and $\left[F^{5} U\right] R N A$ proposed by Santi [30]. 
A

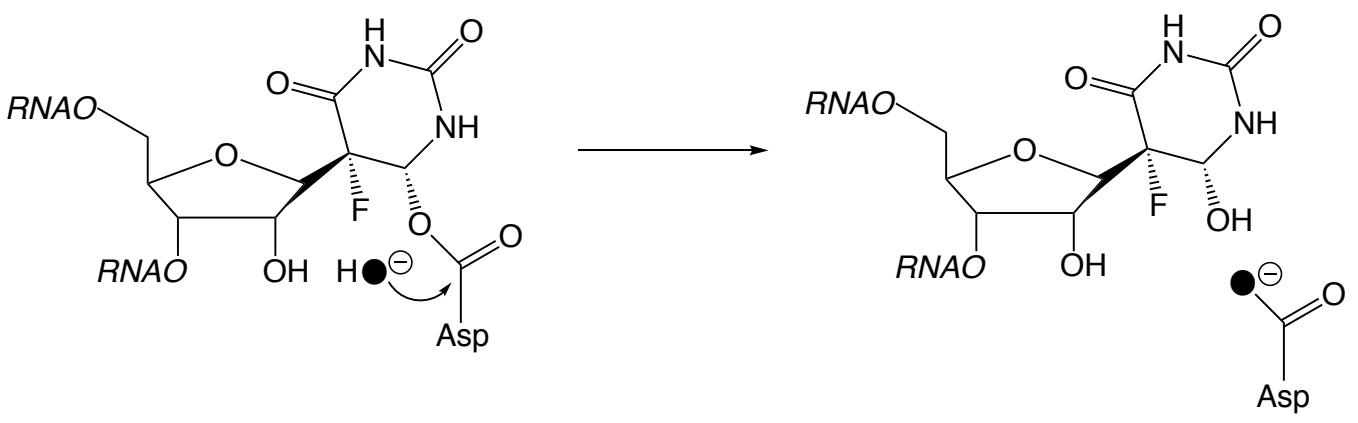

B

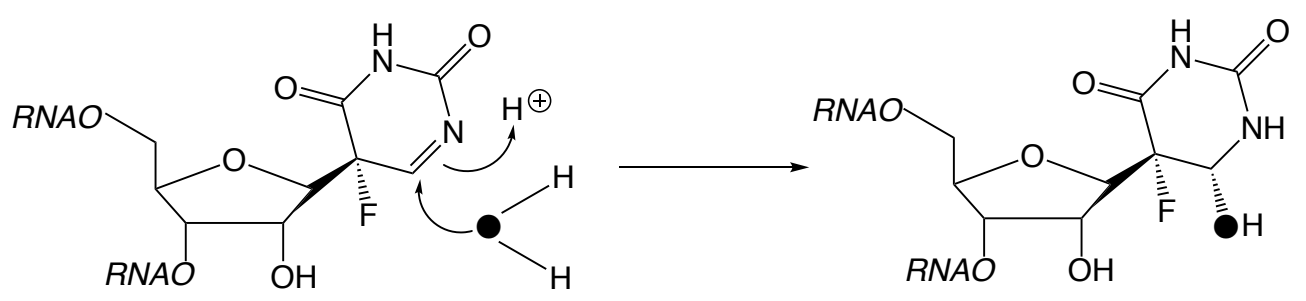

Figure 1.6: ${ }^{18} \mathrm{O}$ labeling scheme. A, Ester hydrolysis would result in ${ }^{18} \mathrm{O}$ incorporation into the conserved Asp. B, Direct hydration of the rearranged product of $\mathrm{F}^{5} \mathrm{U} .{ }^{18} \mathrm{O}$ is abbreviated with a filled $\mathrm{O}$. 


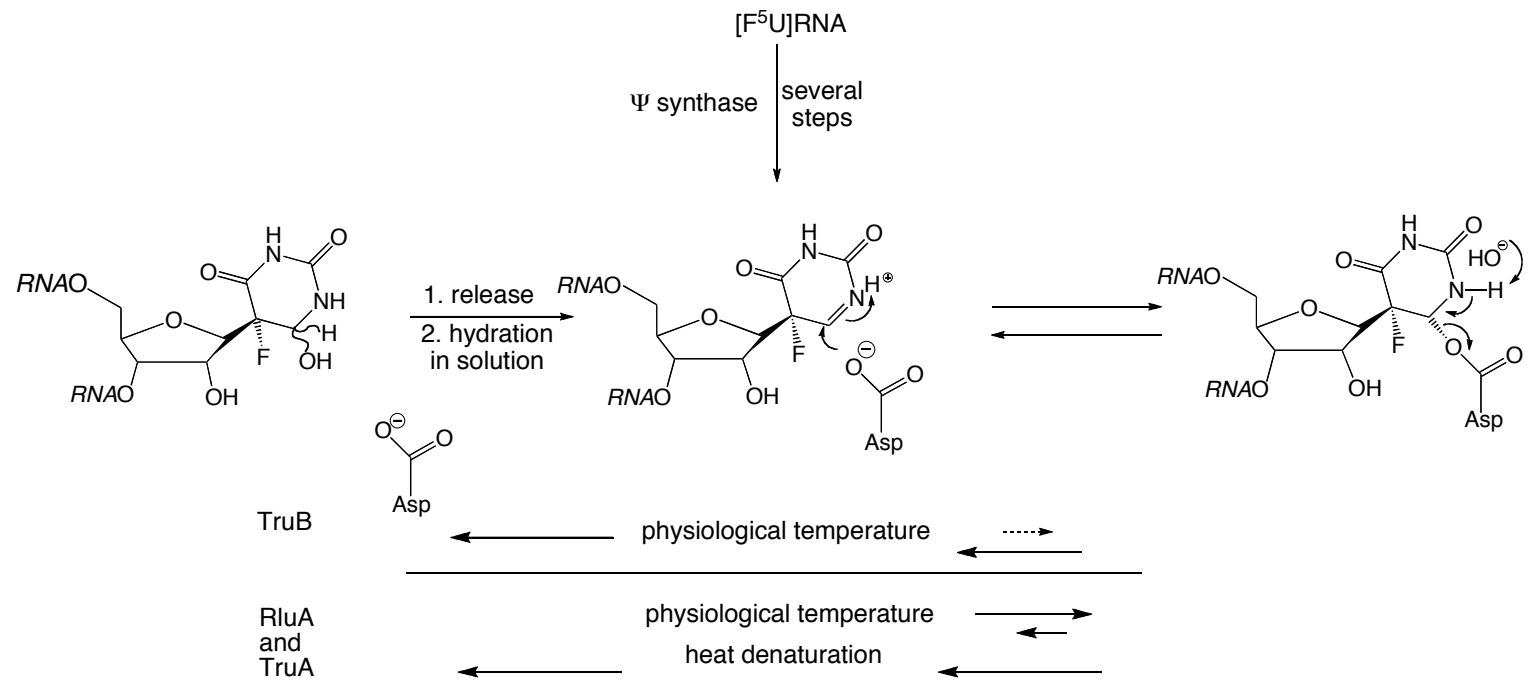

Figure 1.7: A consistent scheme for the handling of $F^{5} U$ in RNA by different $\Psi$ synthase [38].

Since uridine rather than cytidine follows $F^{5} \mathrm{U}$ in $\left[\mathrm{F}^{5} \mathrm{U}\right] \mathrm{ASL}$, the dinucleotide products of $\mathrm{F}^{5} \mathrm{U}$ explain the different HPLC behavior between TruB and RluA products. Subsequent NMR and MS analysis confirmed the formation of two RluA products that are both dinucleotides with uridine and comigrate under HPLC conditions [38].

To investigate the mechanism further, the full structural elucidation of the two products of TruB was undertaken by Mueller and Miracco [39]. NMR results showed that the difference between the two products was at $\mathrm{C} 2$ ' of its pentose ring, which means the minor product is the arabino isomer whereas the major product was the ribo isomer (Figure 1.8). For the formation of the arabino product, epimerization at $\mathrm{C} 2$ ' must occur, which requires deprotonation from the "top" face to form a glycal intermediate followed by reprotonation from the "bottom" face. To determine whether the protonation at $\mathrm{C} 2$ ' is 
directly from solution or an active site acid, reactions of RNA containing either $U$ or $F^{5} U$ with TruB and RluA were run in buffer made with deuterated water, and the products were examined for the incorporation of deuterium into a $\mathrm{C}^{\prime}$ ' position. No "wash-in" was observed with either TruB or RluA, indicating that no direct protonation from solution occurred; therefore, the essential Asp must transfer the proton removed from $U$ to the "wrong" face of the glycal intermediate to generate an arabino isomer [40]. This result strongly disfavors the Michael mechanism because the Asp would be tied up in an ester bond, making it unable to protonate $\mathrm{C} 2$ '. The acylal mechanism can accommodate the arabino product of $\mathrm{F}^{5} \mathrm{U}$ because the decreased nucleophilicity of the anion of 5fluorouridine versus uracil provides a longer lifetime of the acylal intermediate, which is in equilibrium with an oxocarbenium species and the free conserved Asp. The acidity of C2' in the oxocarbenium species would facilitate deprotonation by the conserved Asp, and reprotonation from the opposite face would result in an arabino product (Figure 1.9).

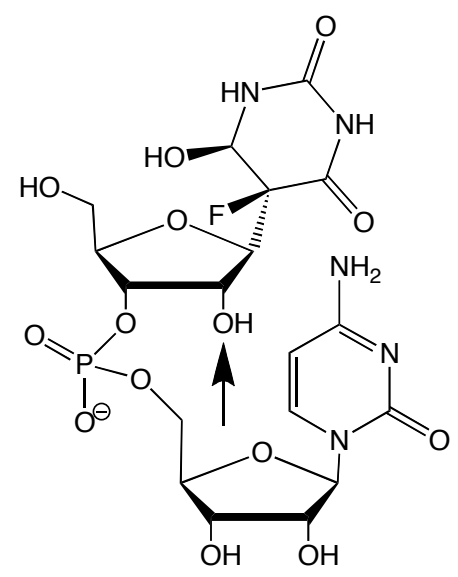

major product: ribo

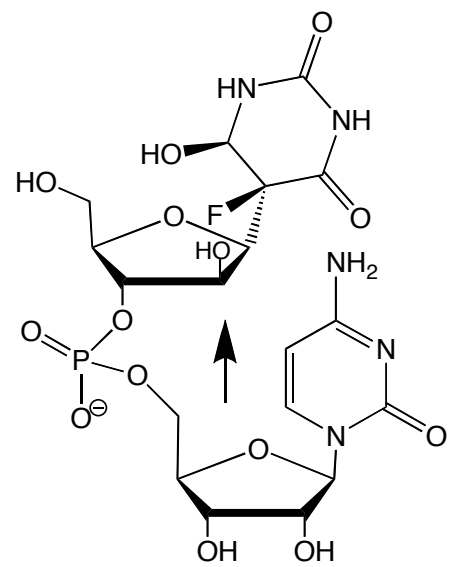

minor product: arabino

Figure 1.8: The major and minor products of $F^{5} U^{*}$ differ in stereo configuration at C2' [39] 


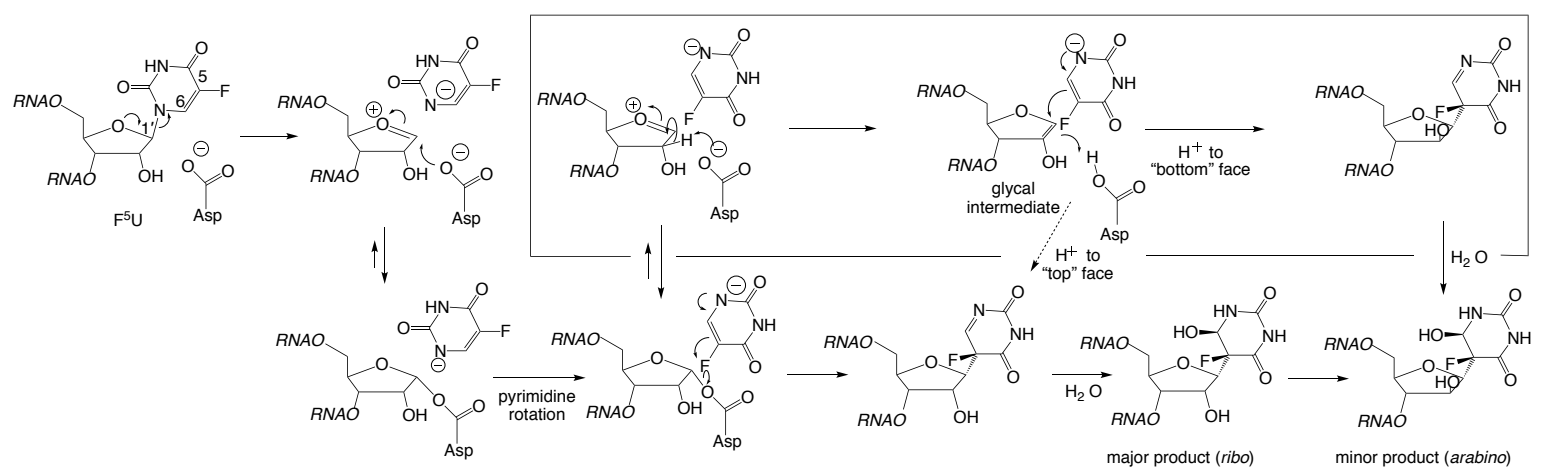

Figure 1.9: The acylal mechanism recast to account for the formation of the arabino product of. The boxed manifold exists only for $F^{5} U$ because of the increased life time of the acylal intermediate, which is equilibrium with the oxocarbenium ion. [39]

The existence of the glycal intermediate opens a new mechanistic possibility: the "glycal mechanism" (Figure 1.10), which can easily explain both the major and minor products of $\mathrm{F}^{5} \mathrm{U}$ (Figure 1.11). With normal substrate (RNA containing $U$ ), the mechanism begins with the deprotonation at $\mathrm{C} 2^{\prime}$ to eliminate pyrimidine ring and form the glycal intermediate, followed by rotation of the detached pyrimidine ring. Reattachment at C5 forms the new C-glycosidic bond with reprotonation of $\mathrm{C} 2$ '. Deprotonation at C5 yield $\Psi$ and completes the isomerization.

To test if the $\Psi$ synthases proceeds through the glycal mechanism, the $2^{\prime}-$ deuterated stem-loop substrates for TruB and RluA were prepared, and their reaction rates were compared with unlabeled substrates. The observed kinetic isotope effects with both TruB and RluA clearly indicate that deprotonation or reprotonation of $\mathrm{C}^{\prime}$ is 
partially rate-limiting, which provides direct evidence for the operation of glycal mechanism during the conversion of $\mathrm{U}$ to $\Psi[40]$.

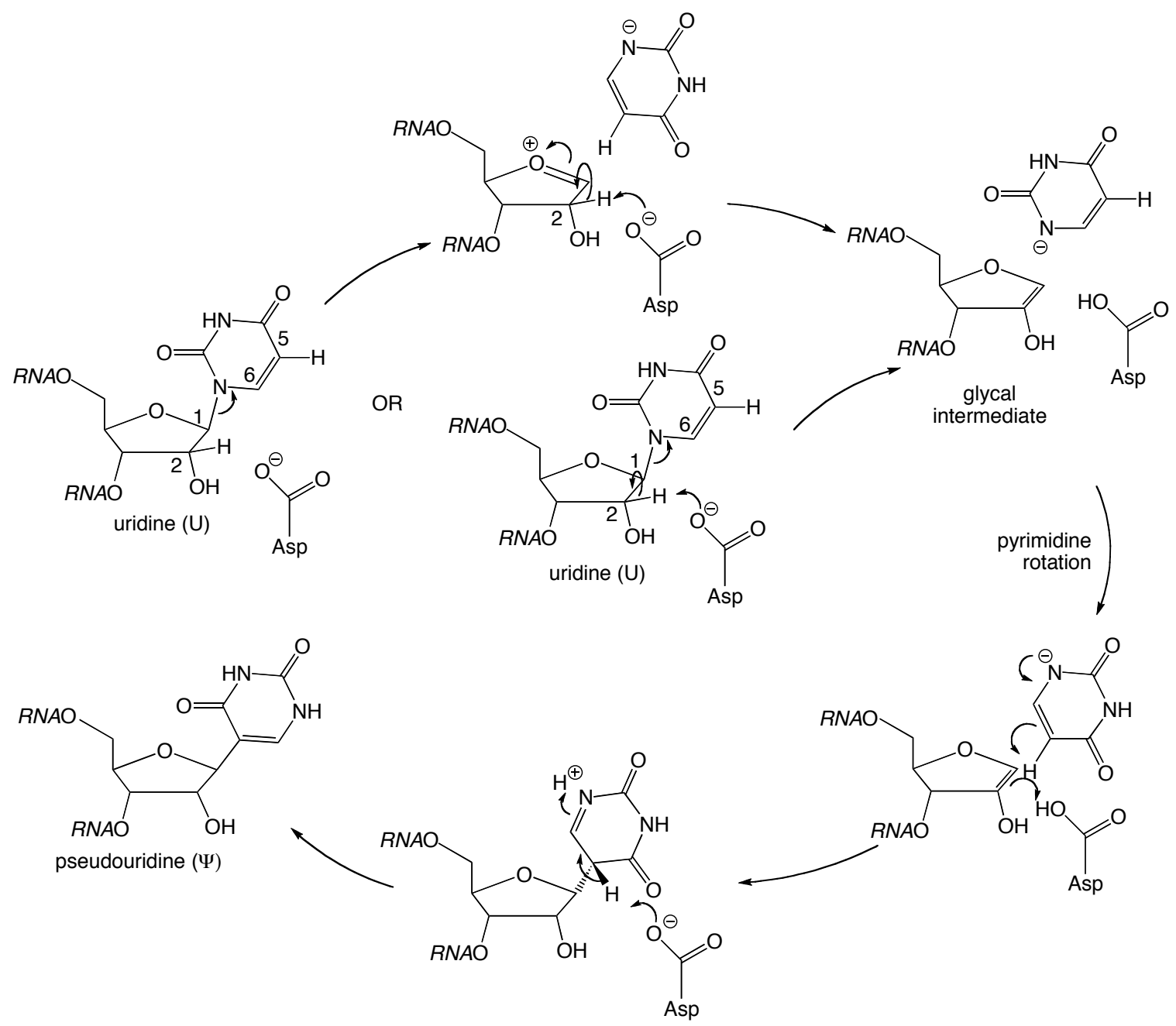

Figure 1.10: The "glycal mechanism" for $\Psi$ formation. The elimination of uracil proceeds through either a concerted (lower path) or step-wise (upper path) to form a glycal intermediate. After the $\mathrm{C}$-glycoside rearrangement, $\mathrm{C2}$ ' is reprotonated by the conserved Asp, followed by deprotonation to generates $\Psi$. [39] 

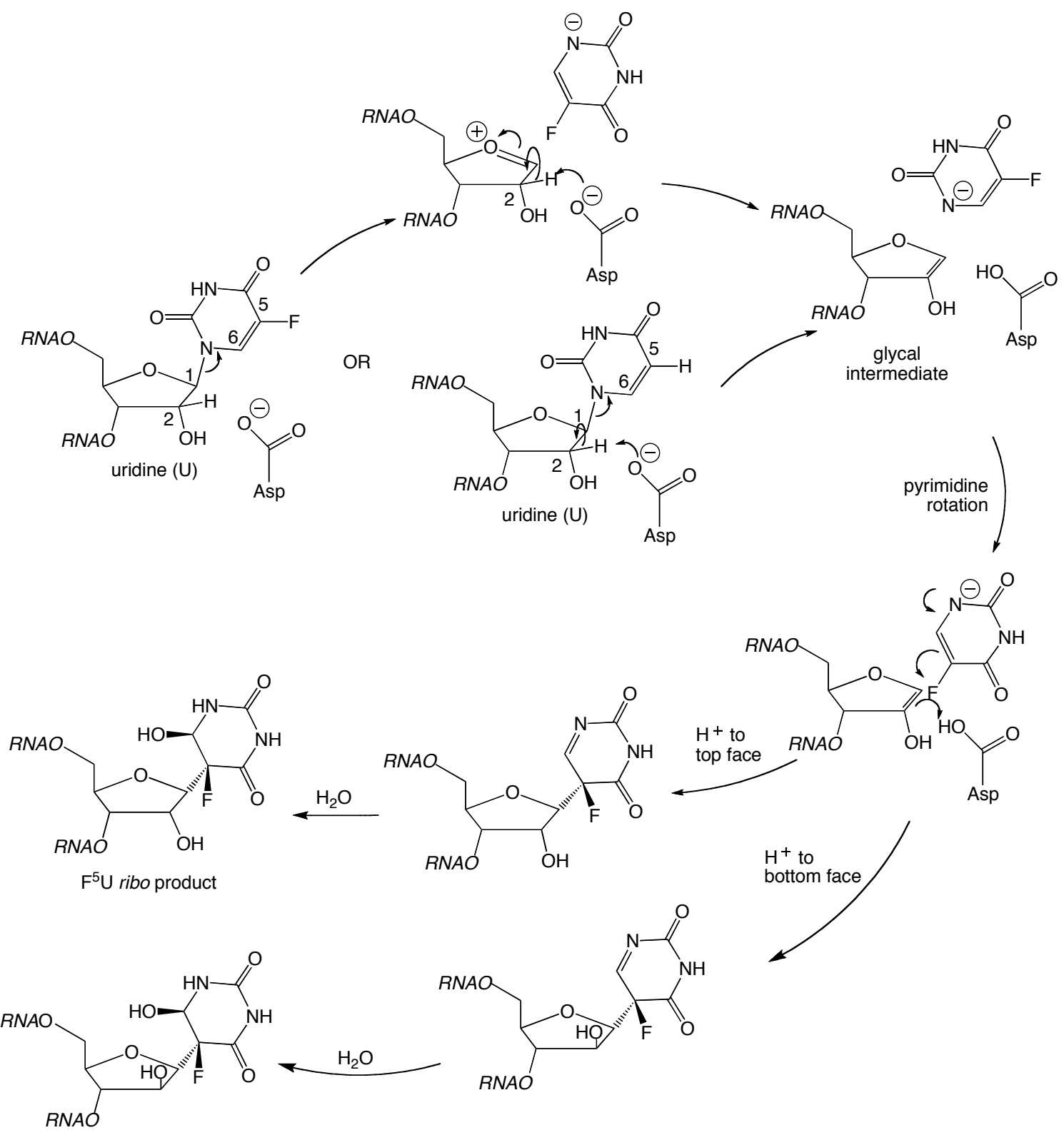

$\mathrm{F}^{5} \mathrm{U}$ arabino product

Figure 1.11: The "glycal mechanism" with $F^{5} U$. Reprotonation from the "bottom" face of the glycal ring yields the arabino product of $\mathrm{F}^{5} \mathrm{U}$. 
The Mueller group proposed a mildly revised scheme to account for the arabino product of $\mathrm{F}^{5} \mathrm{U}$ (Figure 1.12). The formation of products of $\mathrm{F}^{5} \mathrm{U}$ proceed through either the glycal mechanism or the acylal mechanism (recast for the observed arabino product) to rearranged $\mathrm{F}^{5} \mathrm{U}$.

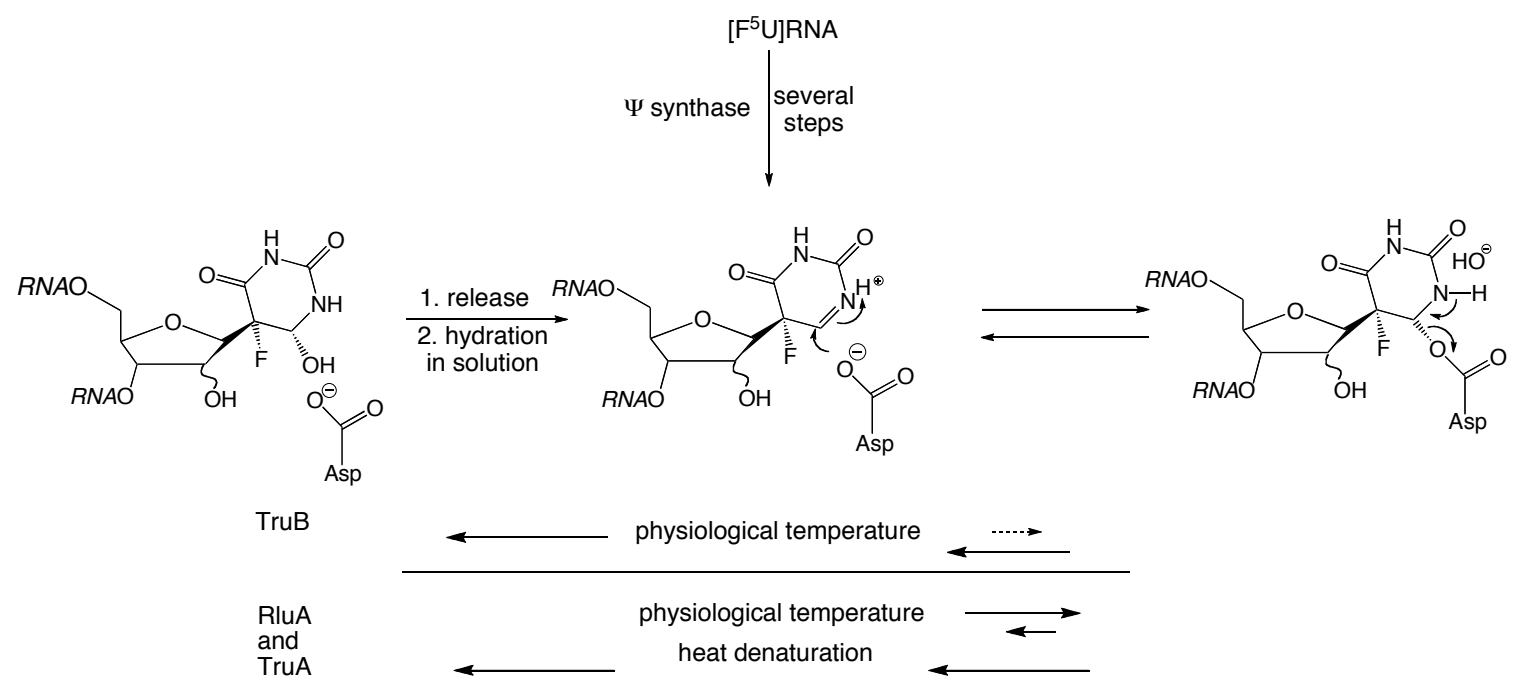

Figure 1.12: A scheme proposed by the Mueller group consistent with all observations, including the arabino product of $\mathrm{F}^{5} \mathrm{U}$. 
4-Thiouridine as a mechanistic probe. Three different mechanisms have been proposed for the $\Psi$ synthases: the Michael (Figure 1.3), acylal (Figure 1.4), and glycal (Figure 1.10) mechanisms. To explain both the ribo and arabino products of $\mathrm{F}^{5} \mathrm{U}$, the Mueller group proposed the glycal mechanism for the $\Psi$ synthases, which is formulated with deprotonation at $\mathrm{C}^{\prime}$ by the conserved Asp to form the glycal intermediate. $\mathrm{O}^{2}$ of uracil could also deprotonate at $\mathrm{C} 2$ ' (Figure 1.13); however, in this case, the proton must migrate to the conserved Asp in order to reprotonate at $\mathrm{C} 2{ }^{\prime}$ from the opposite face to yield the arabino product since the bulky pyrimidine ring may not allow $\mathrm{O}^{2}$ access the "bottom face" of the glycal intermediate. In the crystal structures of the glycal complexes, $\mathrm{O}^{2}$ of fluorouracil is positioned directly above $\mathrm{C} 2$ ' in a good position to act as the base for glycal formation [41].

To test if $\mathrm{O}^{2}$ is the general base, the isomerized $\mathrm{U}$ will be replaced with 4thiouridine $\left(s^{4} U\right)$. Some bacteria naturally have $s^{4} U$ at position 8 of several tRNA, and this $s^{4} U$ not only stabilizes the fold of the tRNA $[42,43]$ but also plays an important role as a photosensor for near-UV light [44]. Replacing oxygen with sulfur at position 4 of the pyrimidine ring results in a significantly lower $\mathrm{p} K_{\mathrm{a}}$ for $\mathrm{s}^{4} \mathrm{U}(8.2)$ than for $\mathrm{U}(9.3)$ [42], making the anion of 4-thiouracil more stable and a better leaving group than the anion of uracil itself and hence increasing the rate of reaction. However, the lower $\mathrm{p} K_{\mathrm{a}}$ of $\mathrm{s}^{4} \mathrm{U}$ also means that 4-thiouracil(ate) is a weaker base than uracil(ate); therefore deprotonation of $\mathrm{C} 2$ ' should slow, thus decreasing the rate of reaction. The rate of the overall reaction depends on two processes: leaving group departure and deprotonation of $\mathrm{C}^{\prime}$, and $\mathrm{s}^{4} \mathrm{U}$ is expected to have opposite effects on the speed of each. A slower rate of overall reaction will imply that $\mathrm{O}^{2}$ is the general base since slower deprotonation is the expected effect of 
$\mathrm{s}^{4} \mathrm{U}$ substitution. A faster rate is less informative because $\mathrm{O}^{2}$ could still be the base that deprotonates $\mathrm{C} 2$, but the effect of being a better leaving group dominates. To ensure $\mathrm{s}^{4} \mathrm{U}$ is handled as a substrate and to identify the products, assays of $s^{4} \mathrm{U}$ with TruB and RluA were performed and analyzed by HPLC. This work with $s^{4} U$ in a RNA substrate is described in Chapter 3 of this thesis.
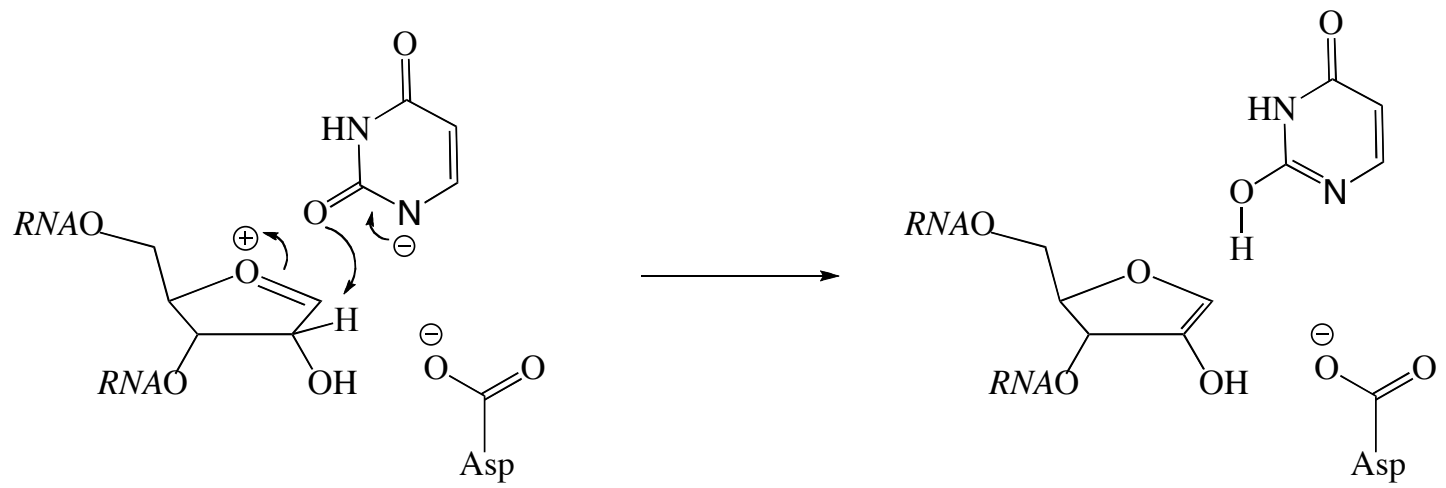

Figure 1.13: Deprotonation at $\mathrm{C2}^{\prime}$ by $\mathrm{O}^{2}$. The proton then migrates to $\mathrm{O}^{4}$ or the conserved Asp to reprotonate at $\mathrm{C2}^{\prime}$. Since neither $\mathrm{O}^{2}$ nor $\mathrm{O}^{4}$ seem likely to be able to access the "bottom" face of the glycal intermediate, the arabino product of $F^{5} U$ requires migration of the removed proton to the conserved Asp. 


\section{CHAPTER II}

\section{MECHANISTIC INVESTIGATION OF Y96F RluA USING}

\section{ASL AND ASL CONTAINING 5-FLUOROURIDINE}

\subsection{Introduction}

In chapter 1 , three $\Psi$ synthase mechanisms were presented, and they all involve an active site aspartic acid residue (Asp) acting as a nucleophile or a base $[34,39]$. In the "Michael mechanism", the conserved Asp acts as a nucleophile to attack C6 of the pyrimidine ring to form a Michael adduct (Figure 1.3). The alternative "acylal mechanism" instead proposes a nucleophilic attack by the conserved Asp on $\mathrm{C} 1^{\prime}$ of the ribose ring (Figure 1.4). The third mechanism is the "glycal mechanism", which involes the conserved Asp acting as base to deprotonate at $\mathrm{C} 2$ ' to form a glycal intermediate (Figure 1.10). Huang and co-workers noted a conserved tyrosine (Tyr) residue in the active site in four of the five families of $\Psi$ synthases (Phe in the TruD family) and conducted site-directed mutagenesis on this Tyr [45]. When Y76F TruB was incubated with natural RNA substrate, no conversion of $U$ to $\Psi$ was observed. However, when $\mathrm{F}^{5} \mathrm{U}$ replaced the isomerized $\mathrm{U}$ in the stem-loop, Y76F TruB catalyzes the reaction of [F $\left.\mathrm{F}^{5} \mathrm{U}\right] \mathrm{RNA}$, making a rearranged and hydrated product just like wild-type TruB [45]. Based on these observations, Huang concluded that the hydroxyl group in the side chain of Tyr-76 must play a critical role in the final step of the reaction, which is deprotonation 
at $\mathrm{C} 5$ to form the product of $\Psi$ (Figure 2.1). This step does not happen with $\left[\mathrm{F}^{5} \mathrm{U}\right] \mathrm{RNA}$ since a base cannot remove the fluorine as it does a proton. The rationale seems to be sound; however, there is evidence arguing against the role of Tyr-76 serving as a general base. First, if Tyr-76 is a general base and only conducts the final step of the reaction (removes the proton from $\mathrm{C} 5$ of rearranged $\mathrm{U}$ ), then the other steps should still occur, allowing the rearrangement of uridine to the $\mathrm{C}$-glycoside. Since the intermediate is more polar than $\mathrm{U}$, it would elute at an earlier retention time than $\mathrm{U}$ from a reverse-phase HPLC column, but no new peaks were detected [45]. Second, the $\mathrm{pH}$ profile studies on TruB from the Mueller group shows a descending limb with a $\mathrm{p} K_{\mathrm{a}}$ of 9 , suggesting that the deprotonation of Tyr could slow the reaction by disrupting the electrostatic environment of the active site [46]. Therefore, Mueller and co-workers proposed that Tyr-76 donates either a proton or hydrogen bond to the pyrimidine ring (the leaving group) to facilitate $\mathrm{N}$-glycosidic bond cleavage. Third, the conserved Tyr seen in the first four families of the $\Psi$ synthase was not found in TruD family; instead, Phe residues occupy in this position. Finally, the crystal structure of wild-type RluB with $\left[F^{5} U\right] R N A$ shows a covalent bond of the hydroxyl group of Tyr-140 and the pyrimidine ring of $F^{5} U$ (Figure 2.2) [47]. To confirm the function of Tyr-76, additional experiments are required. As described, in this chapter, Y96F RluA was overexpressed and incubated with both ASL and $\left[F^{5} \mathrm{U}\right] \mathrm{ASL}$ in order to illuminate the function of the conserved Tyr in the formation of $\Psi$ and to test whether results with Y76F TruB are common to another family of $\Psi$ synthases. Reverse-phase HPLC analysis of both intact and digested RNA from each reaction were analyzed. 


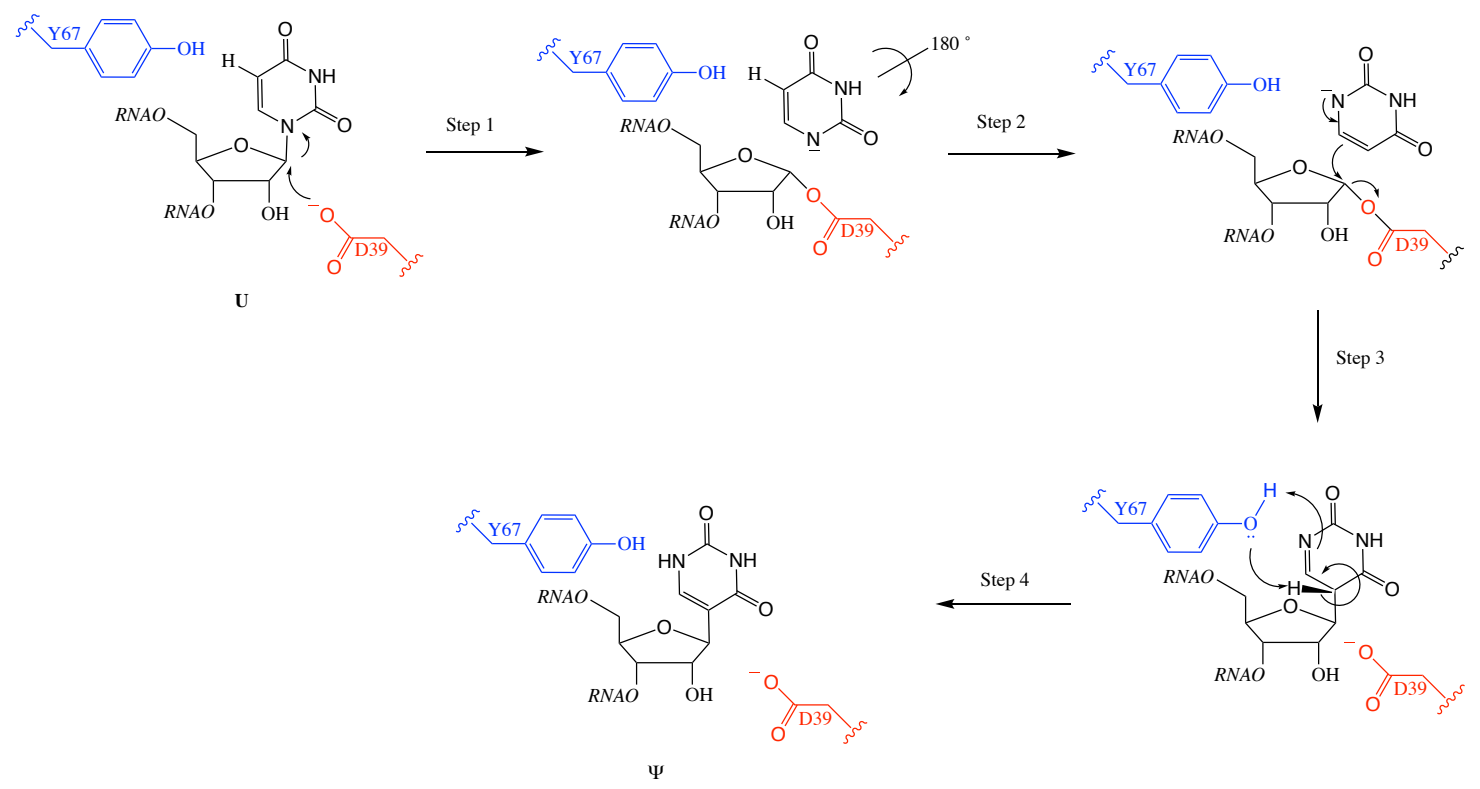

Figure 2.1: Mechanism proposed by Phannachet et al for the $\Psi$ synthases [45]
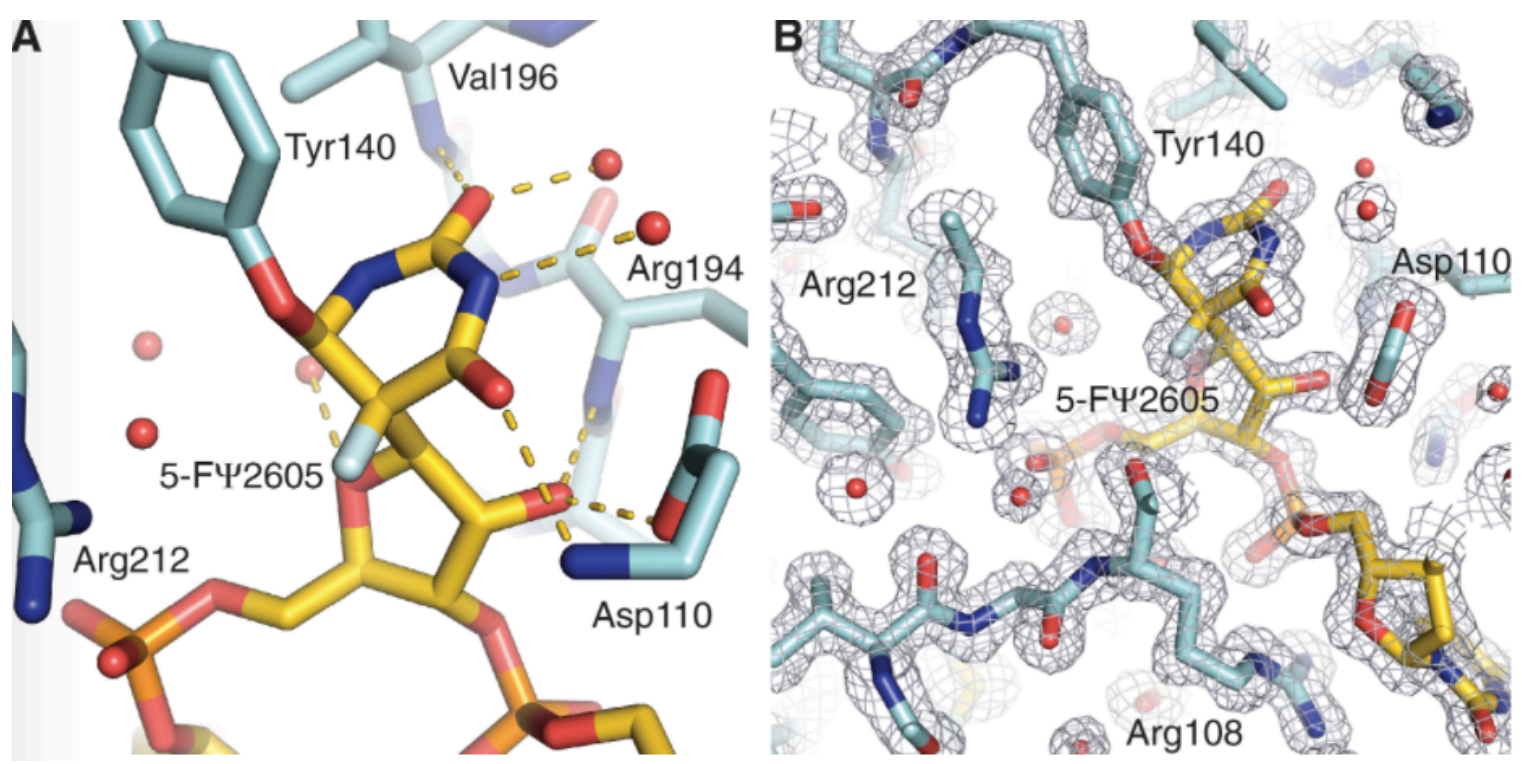

Figure 2.2. The crystal structural shows a covalent bond between Tyr-140 and the pyrimidine ring. From Ref [47] 


\subsection{Experimental}

\subsubsection{Materials}

Competent BLR(DE3) pLysS E. coli cells were purchased from Novagen (Madison, WI). A CLIPEUS $\mathrm{C}_{8} 5-\mu \mathrm{m}$ column $(250 \times 4.6 \mathrm{~mm})$ was purchased from Higgins Analytical, Inc. (Mountain View, CA), and a Zorbax analytical SB-C ${ }_{18} 5-\mu m$ column $(50 \times 4.6 \mathrm{~mm})$ was purchased from Agilent (Santa Clara, CA). Ni-NTA superflow resin and QIAprep Spin Mini prep kits were purchased from Qiagen (Chatsworth, CA). S1 nuclease and calf intestinal alkaline phosphatase were purchased from Promega (Madison, WI). Oligonucleotide ASL (5'-GGGGAUUGAAAAUCCCC$\left.3^{\prime}\right)$ and $\left[\mathrm{F}^{5} \mathrm{U}\right] \mathrm{ASL}$ (5'-GGGGAF$\left.{ }^{5} \mathrm{UUGAAAAUCCCC}^{\prime} 3^{\prime}\right)$ were purchased from

Dharmacon (Lafayette, CO). Ultra-pure deionized water was obtained using a Millipore ${ }^{\circledR}$ Milli-Q integral system (Billerica, MA) equipped with a $0.2 \mu \mathrm{m}$ filter. Laemmli buffer (2×) was $120 \mathrm{mM}$ Tris $\bullet \mathrm{HCl}$ buffer, $\mathrm{pH}$ 6.8, containing SDS (4\%, w/v), glycerol (20\%, $\mathrm{v} / \mathrm{v})$, and bromophenol blue $(0.02 \%, \mathrm{w} / \mathrm{v})$. RNA loading dye $(2 \times)$ was $95 \%$ aqueous formamide containing bromophenol blue $(0.025 \%$, w/v), xylene cyanol $(0.025 \%$, w/v), and $\operatorname{EDTA}(0.5 \mathrm{mM})$.

\subsubsection{Overexpression and Purification of Y96F RluA}

Overexpression. An overnight culture of BLR(DE3) pLysS/pBH222 was used to inoculate LB broth $(1 \mathrm{~L})$ in a baffled flask and shaken vigorously at $37{ }^{\circ} \mathrm{C}$. When $\mathrm{OD}_{600}$ reached $0.4-0.6$, isopropyl- $\beta$-D-thiogalactopyranoside $(4 \mathrm{~mL}, 100 \mathrm{mM})$ was added (0.4 $\mathrm{mM}$ final concentration). The cells were harvested $3 \mathrm{~h}$ after induction $\left(\mathrm{OD}_{600}=1.1-\right.$ 1.2). The cells were centrifuged at $6,000 \mathrm{~g}$ for $30 \mathrm{~min}$ at $4{ }^{\circ} \mathrm{C}$ and resuspended in lysis buffer $(10 \mathrm{~mL})$, which is $50 \mathrm{mM}$ sodium phosphate buffer, $\mathrm{pH} 8.0$, containing imidazole 
$(10 \mathrm{mM})$ and $\mathrm{NaCl}(300 \mathrm{mM})$. The suspensions were quick-frozen and stored at $-80{ }^{\circ} \mathrm{C}$.

Purification. The cell pellets containing overexpressed Y96F RluA were thawed and sonicated, and then the lysate was centrifuged $(13,500 \mathrm{~g}$ for $30 \mathrm{~min})$ to pellet cell debris. A slurry of Ni-NTA superflow resin ( $3 \mathrm{~mL}$ settled resin volume) was added to the supernatant and nutated for $1 \mathrm{~h}$ to bind the His-tagged Y96F RluA to the resin. The resin was pelleted $(7500 \mathrm{~g}$ for $30 \mathrm{~min})$, resuspended in lysis buffer $(3 \mathrm{~mL})$, and packed into a column. The column was washed $(3 \times 5 \mathrm{~mL})$ with $50 \mathrm{mM}$ sodium phosphate buffer, $\mathrm{pH} 8.0$, containing imidazole $(20 \mathrm{mM})$ and $\mathrm{NaCl}(300 \mathrm{mM})$. The bound Y96F RluA was eluted $(2 \times 5 \mathrm{~mL})$ with $50 \mathrm{mM}$ sodium phosphate buffer, $\mathrm{pH} 8.0$, containing imidazole (250 $\mathrm{mM})$ and $\mathrm{NaCl}(300 \mathrm{mM})$. The elutions were dialyzed in $20 \mathrm{mM}$ HEPES buffer, $\mathrm{pH} 7.5$, EDTA $(0.5 \mathrm{mM}), \beta$-mercaptoethanol $(1 \mathrm{mM})$, and glycerol $(5 \% \mathrm{v} / \mathrm{v})$ for $2 \times 2 \mathrm{~h}$. The Y96F RluA was then further purified by POROS HS anion exchange chromatography, eluting with a linear gradient of $\mathrm{KCl}(0-1 \mathrm{M})$ in $20 \mathrm{mM}$ HEPES buffer, $\mathrm{pH} 7.5$, containing EDTA $(0.5 \mathrm{mM}), \beta$-mercaptoethanol $(1 \mathrm{mM})$, and glycerol $(5 \% \mathrm{v} / \mathrm{v})$. Each protein-bearing fraction $(1 \mathrm{~mL})$ was analyzed for purity by SDS-PAGE.

RNase Activity Assays. The fractions containing Y96F RluA were tested for RNase contamination. The RluA-bearing fractions from POROS HS chromatography were assayed at a constant protein concentration $(100 \mathrm{nM})$. Each RluA-bearing fraction $(100 \mathrm{nM})$ was incubated with RNA markers at $37{ }^{\circ} \mathrm{C}$ for $1 \mathrm{~h}$, which were then analyzed by urea-PAGE. Fractions that were pure by SDS-PAGE and RNase-free were combined and dialyzed $(2 \times 2 \mathrm{~h})$ against $23.5 \mathrm{mM}$ HEPES buffer, $\mathrm{pH} 7.5$, containing $\mathrm{KCl}$ (176.5 mM), EDTA (0.58 mM), DTT $(0.58 \mathrm{mM})$, and glycerol $(5 \% \mathrm{v} / \mathrm{v})$. Y96F RluA concentrations were determined using $\mathrm{A}_{280}$ and $\varepsilon_{280}=30700 \mathrm{M}^{-1} \mathrm{~cm}^{-1}$. 


\subsubsection{Deprotection and Purification of 2'-ACE RNA Oligonucleotides}

Synthetic oligonucleotide (17-mer) stemloop (ASL or [ $\left.\left.\mathrm{F}^{5} \mathrm{U}\right] \mathrm{ASL}\right)$ was deprotected according to the manufacturer's protocol. Lyophilized ASL or [F $\left.\mathrm{F}^{5} \mathrm{U}\right] \mathrm{ASL}(340 \mathrm{nmol})$ was dissolved in $100 \mathrm{mM}$ acetate buffer, $\mathrm{pH}$ 3.8, made by the addition of tetramethylethylenediamine (TEMED) to a solution of acetic acid, and incubated at $60{ }^{\circ} \mathrm{C}$ for $2 \mathrm{~h}$. The deprotected ASL or [F $\left.\mathrm{F}^{5} \mathrm{U}\right] \mathrm{ASL}$ was lyophilized using a Speed Vac concentrator and then dissolved in water $(100 \mu 1)$. ASL and $\left[\mathrm{F}^{5} \mathrm{U}\right] \mathrm{ASL}$ were further purified by HPLC over a $\mathrm{C}_{8}$ preparatory column (Clipeus $\mathrm{C}_{8} 5 \mu \mathrm{m}, 250 \times 10 \mathrm{~mm}$, Higgins Analytical, Mountain View, CA), eluting with a gradient of acetonitrile $(0-40 \%)$ in $5 \mathrm{mM}$ ammonium acetate buffer, $\mathrm{pH}$ 6.0. The ASL or [ $\left.\mathrm{F}^{5} \mathrm{U}\right] \mathrm{ASL}$ was lyophilized, redissolved in water, and stored at $-20{ }^{\circ} \mathrm{C}$. The final ASL or $\left[\mathrm{F}^{5} \mathrm{U}\right] \mathrm{ASL}$ concentration was determined using $\mathrm{A}_{260}$ and an extinction coefficient $\left(170500 \mathrm{M}^{-1} \mathrm{~cm}^{-1}\right)$ provided by Dharmacon.

\subsubsection{Assay of Y96F RluA Activity}

Reaction of $\boldsymbol{A S L}$. The reaction mixture $(800 \mu \mathrm{L})$ was $50 \mathrm{mM}$ HEPES buffer, $\mathrm{pH} 7.5$, containing sodium chloride $(175 \mathrm{mM})$, DTT $(5 \mathrm{mM})$, EDTA (1 mM), RNase inhibitor (30 units), and ASL $(50 \mu \mathrm{M})$. After pre-equilibration at $37^{\circ} \mathrm{C}$, reaction was initiated by the addition of Y96F RluA (to $5 \mu \mathrm{M}$ ). Aliquots $(100 \mu \mathrm{L}$ ) were removed at various times and immediately heated at $97{ }^{\circ} \mathrm{C}$ for $10 \mathrm{~min}$. The protein precipitate was pelleted by centrifugation, and the supernatant was transferred to a fresh tube. Residual protein was extracted from the supernatant with an equal volume of phenol/chloroform (1:1), and the aqueous layer was removed and transferred to a fresh tube. One tenth volume of $0.3 \mathrm{M}$ sodium acetate buffer $\mathrm{pH}$ 6.0, was added and well-mixed followed by cold absolute ethanol $(330 \mu \mathrm{L})$, and the mixture placed in $-80{ }^{\circ} \mathrm{C}$ for $2 \mathrm{~h}$. The supernatant 
was removed, and the pellet was rinsed with cold $70 \%$ aqueous ethanol $(100 \mu \mathrm{L})$, airdried, and resuspended in $50 \mathrm{mM}$ HEPES buffer $(100 \mu \mathrm{L}), \mathrm{pH} 7.5$, containing sodium chloride $(175 \mathrm{mM})$ and EDTA $(1 \mathrm{mM})$ then passed through a $0.2 \mu \mathrm{m}$ filter before being analyzed by reverse phase HPLC (Clipeus $\mathrm{C}_{18} 5 \mu \mathrm{m}$ column, $150 \times 4.6 \mathrm{~mm}$; Higgins Analytical, Mountain View, CA). RNA was eluted with an acetonitrile gradient by the following program (the first number is the percentage of aqueous acetonitrile, $40 \% \mathrm{v} / \mathrm{v}$, in $25 \mathrm{mM}$ ammonium acetate buffer, $\mathrm{pH} 6.0$; the second number is the elapsed time in minutes): 0,$0 ; 0,3 ; 5,8 ; 15,18 ; 15,23 ; 30,26 ; 50,27.5 ; 50,29 ; 100,30 ; 100,31 ; 0,32$; 0,36 .

Digestion of $\boldsymbol{A S L}$. To confirm the formation of product, ASL was digested after incubation with Y97F RluA and ethanol precipitation. The protocol described above was followed through the phenol/chloroform extraction. The air-dried pellet was resuspended in $50 \mathrm{mM}$ sodium acetate buffer $(100 \mu \mathrm{L}), \mathrm{pH} 4.5$, containing sodium chloride $(280 \mathrm{mM})$ and zinc chloride (4.5 mM). S1 nuclease (100 units) was added; after $1 \mathrm{~h}$ at $37{ }^{\circ} \mathrm{C}$, the digestion mixture was heated to $100{ }^{\circ} \mathrm{C}$ for $5 \mathrm{~min}$ and then cooled on ice. Additional S1 nuclease (100 units) and alkaline phosphatase (5 units) were added, and the digestion mixture was incubated for an additional $3 \mathrm{~h}$ at $37^{\circ} \mathrm{C}$, then passed through a $0.2 \mu \mathrm{m}$ filter and analyzed by reverse-phase HPLC as described for intact ASL.

Reaction of $\left[\boldsymbol{F}^{5} \boldsymbol{U}\right] \boldsymbol{A S L}$. The reaction mixture (1.00 mL) was $50 \mathrm{mM}$ HEPES buffer, pH 7.5, containing sodium chloride (175 mM), DTT (5 mM), EDTA (1 mM), RNase inhibitor (30 units), and $\left[\mathrm{F}^{5} \mathrm{U}\right] \mathrm{ASL}(2 \mu \mathrm{M})$. After pre-equilibration at $37^{\circ} \mathrm{C}$, the reaction was initiated by the addition of Y96F RluA (to $1 \mu \mathrm{M})$. Aliquots $(500 \mu \mathrm{L})$ were removed at $3 \mathrm{~h}$ and immediately incubated at $97{ }^{\circ} \mathrm{C}$ for $10 \mathrm{~min}$. The protein precipitate 
was pelleted by centrifugation, and the supernatant was transferred to a fresh tube. Residual protein was extracted from the supernatant with an equal volume of phenol/chloroform (1:1), and the aqueous layer was removed and transferred to a fresh tube. One tenth volume of $0.3 \mathrm{M}$ sodium acetate buffer, $\mathrm{pH}$ 6.0, was added and wellmixed followed by cold absolute ethanol $(1.65 \mathrm{~mL})$, and the mixture placed at $-80{ }^{\circ} \mathrm{C}$ for $2 \mathrm{~h}$. The supernatant was removed, and the pellet was rinsed with cold $70 \%$ aqueous ethanol $(100 \mu \mathrm{L})$, air-dried, and resuspended in $50 \mathrm{mM}$ HEPES buffer $(100 \mu \mathrm{L}), \mathrm{pH} 7.5$, containing sodium chloride $(175 \mathrm{mM})$ and EDTA $(1 \mathrm{mM})$ then passed through a $0.2 \mu \mathrm{m}$ filter and analyzed by reverse-phase HPLC as described for intact ASL.

Digestion of $\left[\mathbf{F}^{5} \mathbf{U}\right] A S L$. The digestion to nucleosides of $\left[\mathrm{F}^{5} \mathrm{U}\right] \mathrm{ASL}$ before or after incubation with Y96F RluA was performed by the method described above for the digestion of ASL.

\subsubsection{Formation of the Adduct between Y96F RluA and $\left[F^{5} U\right] A S L$}

The adduct between Y96F RluA and [F5 U]ASL was formed by incubating Y96F RluA $(1 \mu \mathrm{M})$ and $\left[\mathrm{F}^{5} \mathrm{U}\right] \mathrm{ASL}(2 \mu \mathrm{M})$ in the reaction buffer for $3 \mathrm{~h}$ at $37{ }^{\circ} \mathrm{C}$. The sample $(60 \mu \mathrm{L})$ was then diluted with $2 \times$ Laemmli buffer $(60 \mu \mathrm{L})$ and split into two samples of equal volume; one was heated at $97{ }^{\circ} \mathrm{C}$ for $10 \mathrm{~min}$, and the other was kept on ice. Aliquots of each sample were analyzed by SDS-PAGE (10\% gel) to verify the presence of adduct, which was indicated by a band that shifted to a higher apparent molecular weight.

\subsection{Results}

\subsubsection{Overexpression and Purification of Y96F RluA}

The expression vector $\mathrm{pBH} 222$ was used to encode Y96F RluA. Protein was 
overexpressed and purified by nickel affinity chromatography followed by cation exchange chromatography. For long term stability, pure fractions of Y96F RluA were combined, concentrated to $2-4 \mathrm{mg} / \mathrm{ml}$, and made up to $20 \%(\mathrm{v} / \mathrm{v})$ with added glycerol, and stored at $-20{ }^{\circ} \mathrm{C}$.

A

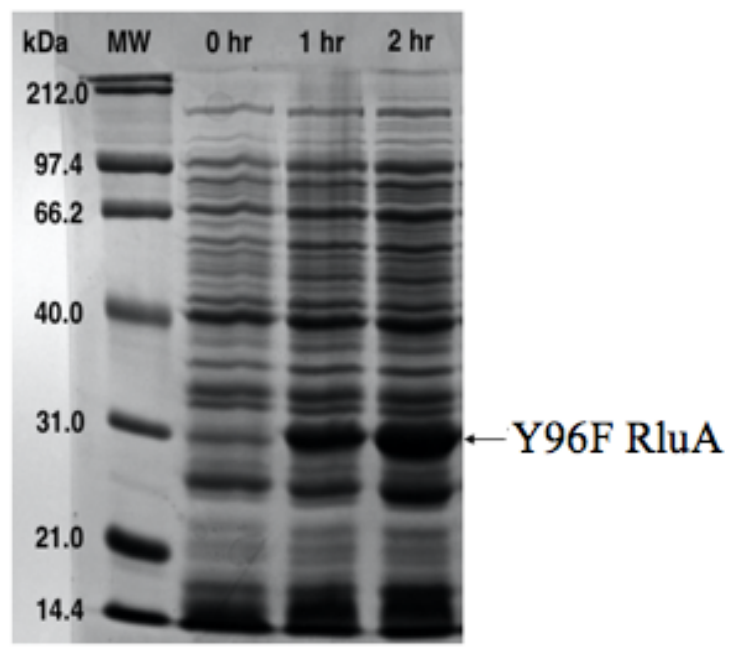

B

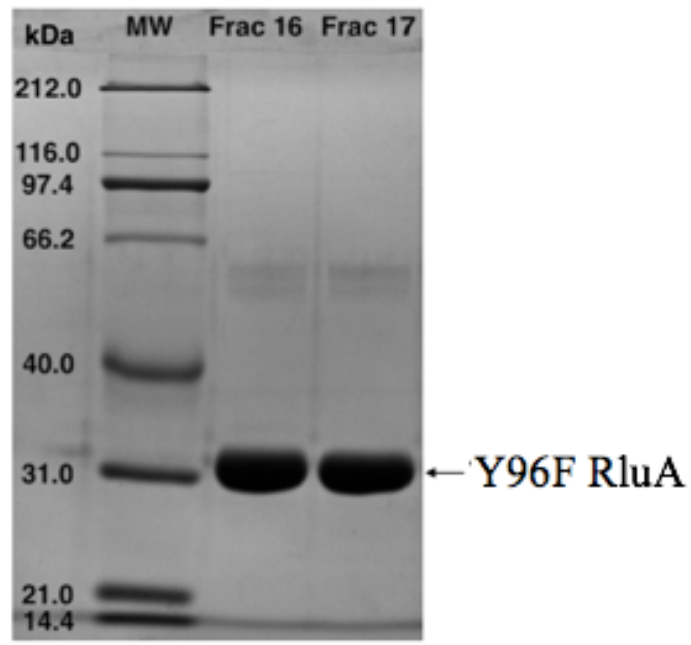

Figure 2.3: SDS-PAGE analysis of the overexpression and purification of Y96F RluA (28 kDA). A, Overexpression of Y96F RluA. B, purified fractions of Y96F RluA. MW, molecular weight markers, wide range (Fisher Scientific; Waltham, MA). 


\subsubsection{Y96F RluA isomerizes uridine and $F^{5} U$ in stem-loop substrate}

To verify that Y96F RluA isomerizes the $\mathrm{U}$ in ASL and $\mathrm{F}^{5} \mathrm{U}$ in $\left[\mathrm{F}^{5} \mathrm{U}\right] \mathrm{ASL}$, both ASL $(50 \mu \mathrm{M})$ and $\left[\mathrm{F}^{5} \mathrm{U}\right] \mathrm{ASL}(2 \mu \mathrm{M})$ were incubated with Y96F RluA $(5 \mu \mathrm{M}$ and $1 \mu \mathrm{M}$, respectively). Intact ASL and $\left[\mathrm{F}^{5} \mathrm{U}\right] \mathrm{ASL}$ were both analyzed by reverse-phase HPLC. The ASL peak shifted to a shorter retention time after incubation with Y96F RluA, which is similar to the behavior of wild-type RluA when it incubated with ASL. However, the HPLC analysis showed less than $11 \%$ conversion of substrate ASL (with $\mathrm{U}$ ) to product ASL (with $\Psi$ ) after $6 \mathrm{~h}$, which is consistent with only a single turnover.

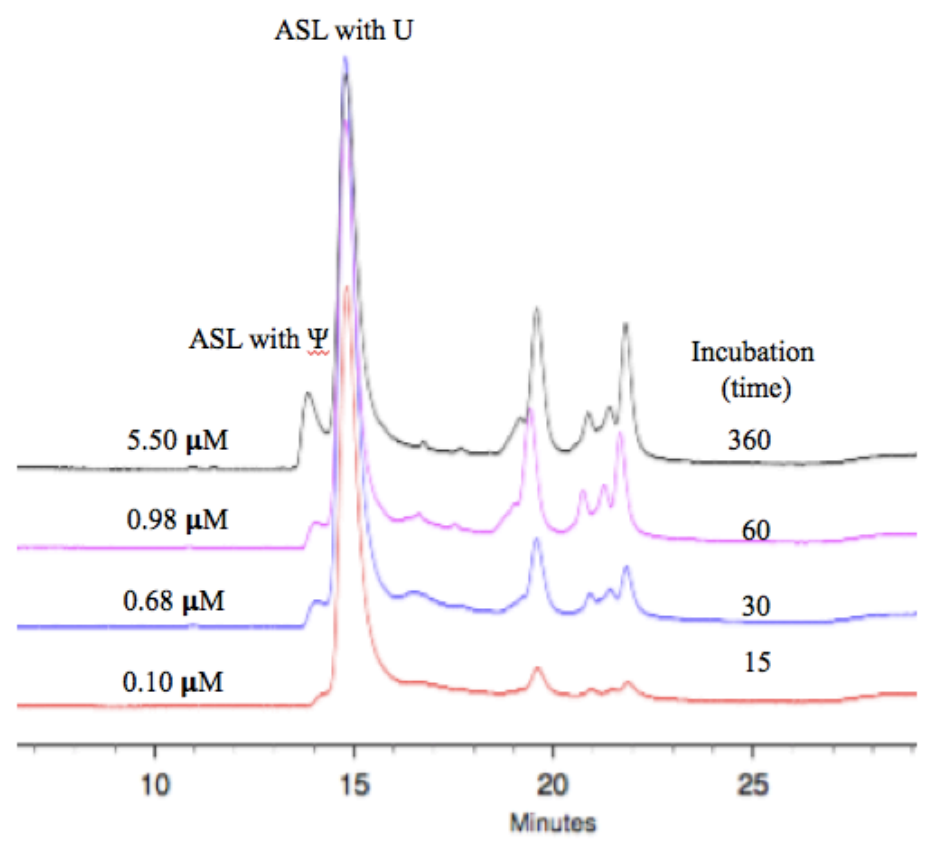

Figure 2.4: Time course for the conversion of ASL $(50 \mu \mathrm{M})$ upon incubation with Y96F RluA $(5 \mu M)$. HPLC traces showing the increase in $\Psi$ with time. The major peaks are substrate ASL (with $U$ ) at 15 min and product (with $\Psi$ ) at 14 min. 
The Y96F RluA also modified [ $\left.\mathrm{F}^{5} \mathrm{U}\right] \mathrm{ASL}$ and shifted it to a greater retention time, which is the behavior of wild-type RluA. Since the Y96F RluA reaction was conducted with excess substrate, unreacted $\left[\mathrm{F}^{5} \mathrm{U}\right] \mathrm{ASL}$ remained. The peak integration indicated $75 \%$ of $\left[\mathrm{F}^{5} \mathrm{U}\right] \mathrm{ASL}$ was converted to product after $4 \mathrm{~h}$, which is 1.5 turnovers per Y96F RluA present. To ensure that the shift was due to formation of the products of $\left[F^{5} U\right] A S L$ (hereafter, the product of $\mathrm{F}^{5} \mathrm{U}=\mathrm{F}^{5} \mathrm{U}^{*}$ ), a complete reaction of $\left[\mathrm{F}^{5} \mathrm{U}\right] \mathrm{ASL}$ after incubation with Y96F RluA was digested to free nucleosides and analyzed by reverse-phase HPLC. Before incubation of $\left[F^{5} U\right] A S L$ with Y96F RluA, peaks corresponding to $C, U, F^{5} U, G$, and A were observed. After incubation, the $\mathrm{C}, \mathrm{U}, \mathrm{G}$, and A peaks remained, but the $\mathrm{F}^{5} \mathrm{U}$ peak was reduced, and a new peak appeared at $4.8 \mathrm{~min}$. The new of peak was observed at 4.8 min when $\left[\mathrm{F}^{5} \mathrm{U}\right] \mathrm{ASL}$ incubated with Y96F RluA, indicating the formation of $\mathrm{F}^{5} \mathrm{U}^{*}$.

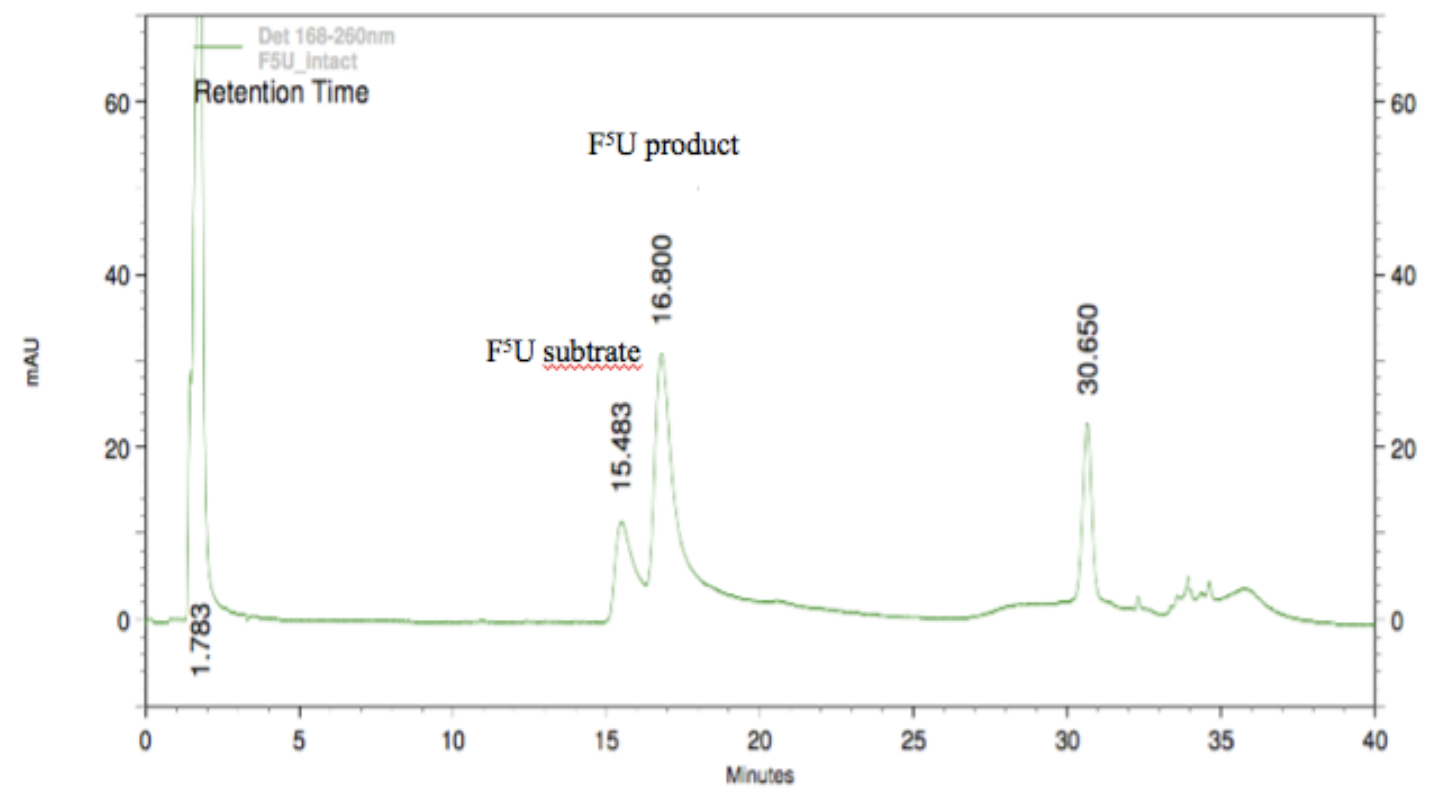

Figure 2.5: HPLC analysis of [ $\left.F^{5} \mathrm{U}\right] \mathrm{ASL}$ after incubation with Y96F RluA. The peak at $\mathbf{1 5 . 5} \mathbf{m i n}$ is substrate and peak at $\mathbf{1 6 . 8} \mathbf{m i n}$ is product. 


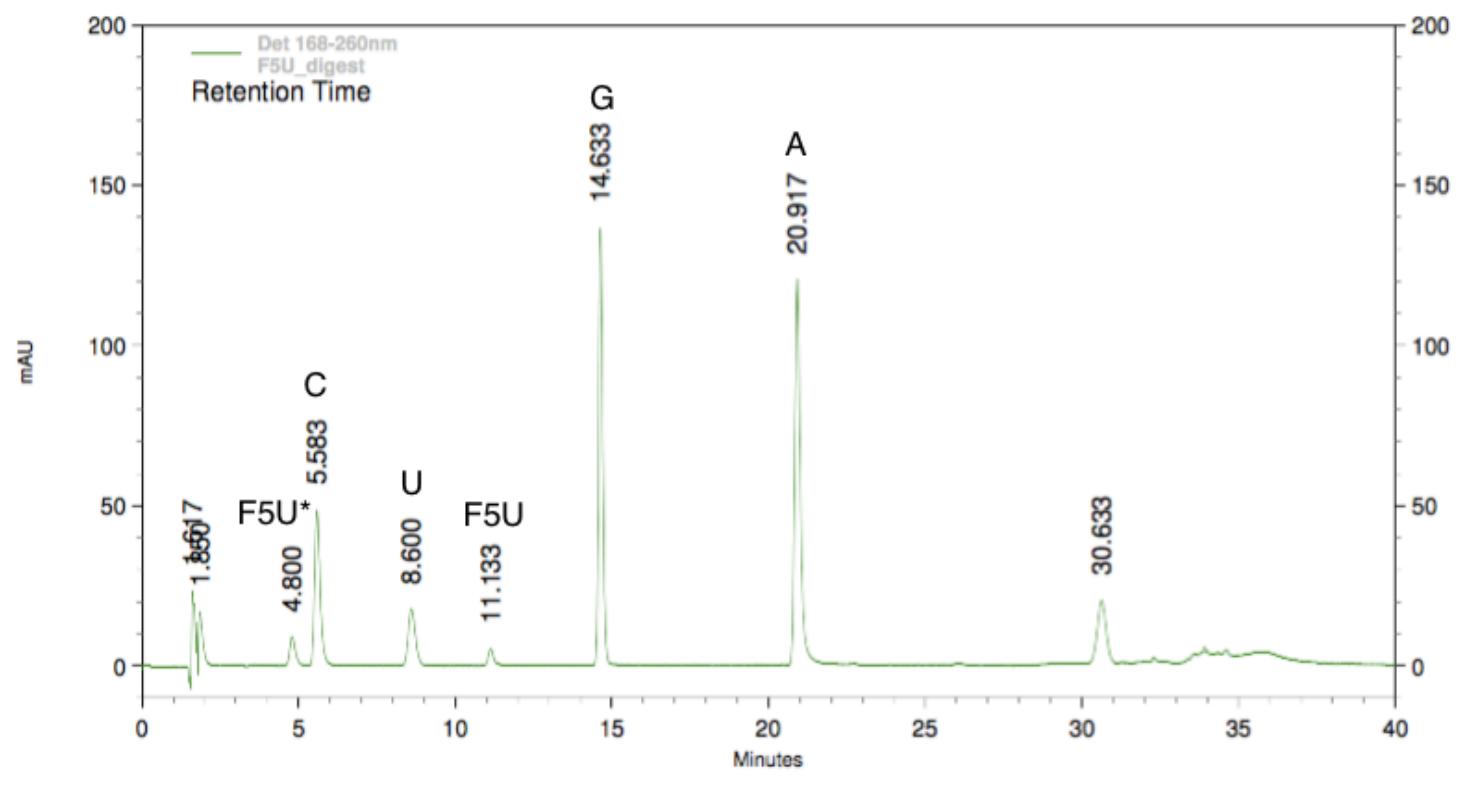

Figure 2.6: Digestion of [ $\left.F^{5} \mathrm{U}\right] \mathrm{ASL}$ after incubated with Y96F RluA.

\subsubsection{Adduct formation between Y96F RluA and $\left[F^{5} U\right] A S L$}

To probe adduct formation, $\left[\mathrm{F}^{5} \mathrm{U}\right] \mathrm{ASL}(2 \mu \mathrm{M})$ was incubated with Y96F RluA $(1 \mu \mathrm{M})$ for $3 \mathrm{~h}$ at $37^{\circ} \mathrm{C}$. After reaction, an aliquot $(60 \mu \mathrm{L})$ was diluted into Laemmli buffer $(60 \mu \mathrm{L})$ and split into two samples of equal volume; one of those was heated at $97{ }^{\circ} \mathrm{C}$ for $10 \mathrm{~min}$, and the other was kept on ice. Aliquots of each sample were analyzed by SDS-PAGE $(10 \%$ gel) to verify the presence of adduct. The gel analysis revealed a new, slower moving band, which indicated that the adduction of $\left[\mathrm{F}^{5} \mathrm{U}\right] \mathrm{ASL}$ and $\mathrm{Y} 96 \mathrm{~F}$ RluA causes a gel shift to a higher apparent molecular weight due to retardation of the protein by the added mass of the RNA. When heated, the normal migration of Y96F RluA is observed, which means that heating disrupts the adduct with release of the RNA from the protein. SDS-PAGE characteristic showed $\sim 40 \%$ adduction of Y96F RluA by the 2-fold excess of [ $\left.\mathrm{F}^{5} \mathrm{U}\right] \mathrm{ASL}$. 


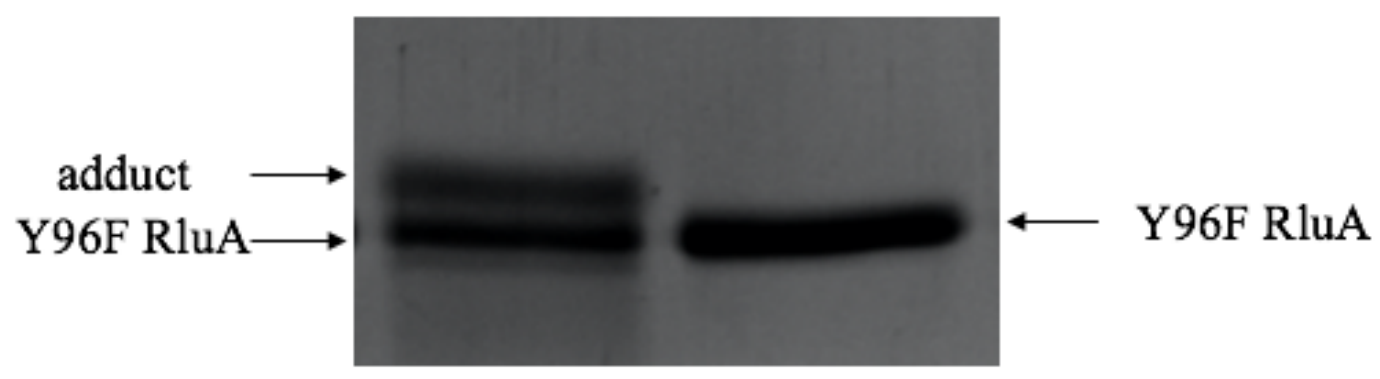

Figure 2.7: SDS-PAGE (10\%) analysis if the formation of the adduct between Y96F RluA and $\left[F^{5} U\right] A S L$. The gel shifted of Y96F RluA upon incubation with [F $\left.{ }^{5} U\right] A S L$ indicates adduct formation (lane 1). Heating disrupts the adduct (lane 2).

\subsection{Discussion}

Phannachet et al. have proposed that the active site Tyr acts as the general base for the isomerization reaction of $U$ to $\Psi$ [45]. If this result is common to another family of $\Psi$ synthases, then the absence of a modified U product is expected when Y96F RluA is incubated with natural substrate (ASL). Instead, $\mathrm{U}$ is converted to $\Psi$ and $\mathrm{F}^{5} \mathrm{U}$ to $\mathrm{F}^{5} \mathrm{U}^{*}$ when Y96F RluA is incubated with ASL and $\left[\mathrm{F}^{5} \mathrm{U}\right] \mathrm{ASL}$, respectively. The products from the action of Y96F RluA have identical elution behavior on reverse-phase HPLC as those from the action of wild-type RluA, indicating the formation of the same products. The appearance of $\Psi$ upon incubation of Y96F RluA with ASL casts doubt on the conclusion of Phannachet et al. about the active site of Tyr serving as general base. At the least, this Tyr is not essential in the final step of the reaction, which is deprotonation at C5 to form the product of $\Psi$.

To determine whether Y96F RluA converts $U$ to $\Psi$ in a time frame similar to wild-type RluA, Y96F RluA (5 $\mu \mathrm{M})$ was incubated with an excess of ASL (50 $\mu \mathrm{M})$, and 
the product was monitored over time by reverse-phase HPLC. The results showed that roughly $10 \%$ conversion of $\mathrm{U}$ to $\Psi$, which means only a single turnover occurred after $6 \mathrm{~h}$ incubation. The slow rate of reaction indicated longer incubation times are required for Y96F RluA to produce detectable $\Psi$, and thus the Tyr might not be essential for activity but does facilitate at least one step of the reaction.

Incubation of Y96F RluA with a two-fold excess of $\left[F^{5} \mathrm{U}\right] \mathrm{ASL}$ results in the formation of an adduct as observed on denaturing SDS-PAGE. However, only $\sim 40 \%$ of the enzyme formed an adduct. The HPLC analysis performed in parallel to the gel analysis revealed $75 \%$ of [ $\left.\mathrm{F}^{5} \mathrm{U}\right] \mathrm{ASL}$ is converted into its hydrated product, which is more than a single turnovers. These results showed that Y96F RluA is not completely driven into the adduct as judged by SDS-PAGE. This behavior of Y96F RluA could arise for two possible reasons. First, Y96F RluA may adopt a specific conformation to bind RNA, and only a part of the protein exists in such a conformation at any given time. Second, an adduct may form between $F^{5} U$ and Tyr-96 instead of the conserved Asp, just like the covalent bond between $\mathrm{F}^{5} \mathrm{U}$ and Tyr-140 of RluB [47].

Based on the observations reported here, it seems that Tyr-96 plays a very important but not essential role in enzyme activity period. The slow rates of reactions and higher concentration of Y96F RluA needed for any reaction indicates that Tyr-96 may provide binding stability or facilitates glycosidic bond cleavage by donating a proton or a hydrogen bond to the uracil(ate). Since the anion of 5-florouracil is a better leaving group than the anion of uracil, the glycosidic bond of $F^{5} U$ can undergo cleavage without the assistance provided by Tyr-96, thus explaining the slower reaction of ASL than $\left[F^{5} U\right] A S L$ when incubated with Y96F RluA. 


\section{CHAPTER III \\ MECHANISTIC INVESTIGATION OF RluA AND TruB \\ USING RNA CONTAINING 4-THIOURIDINE}

\subsection{Introduction}

Pseudouridine synthases are the enzymes that catalyze an isomerization reaction of specific $U$ residues to $\Psi$ in RNAs $[1,2]$. $\Psi$ synthases are classified into six families that share minimal sequence similarity with each other. However, crystal structures of all six families reveal that they share a common fold with a core $\beta$-sheet along with several conserved active site amino acid residues and therefore they likely share a common mechanism [48].

Researchers have used RNA containing 5-fluorouridine as a mechanistic probe. Studies of the interaction of TruB and RluA with $\left[\mathrm{F}^{5} \mathrm{U}\right] \mathrm{RNA}$ revealed that TruB does not form a covalent adduct with $\left[\mathrm{F}^{5} \mathrm{U}\right] \mathrm{RNA}$ but RluA does [36]. However, both enzymes convert $\mathrm{F}^{5} \mathrm{U}$ to rearranged and hydrated products. Two peaks in the HPLC analysis showed that TruB generates two products of $F^{5} \mathrm{U}$, but RluA generated only one product peak from $\mathrm{F}^{5} \mathrm{U}$, which differed from either of the TruB product peaks $[29,36]$. Mass spectrometric analysis and the observation of two resonances in the ${ }^{31} \mathrm{P}$ NMR spectrum confirmed that both TruB products were isolated as dinucleotides containing the cytidine that follow $F^{5} U$ in $\left[F^{5} U\right]$ TSL [38]. The dinucleotide products can explain the difference 
in HPLC retention times between the RluA and the TruB products peaks since uridine rather than cytidine follows $F^{5} U$ in $\left[F^{5} U\right] A S L$. Subsequent NMR and MS experiments from the Mueller group revealed that RluA also converts $\mathrm{F}^{5} \mathrm{U}$ into two products. They are both dinucleotides with uridine and are very similar to the TruB products, confirming that both enzymes generate the same two isomeric products from $F^{5} U$ [38]. NMR experiments by Miracco and Mueller showed that both products of $\mathrm{F}^{5} \mathrm{U}$ from the action of TruB and RluA differ at $\mathrm{C}^{\prime}$ of the pentose ring rather than in the pyrimidine ring: the major product of $\mathrm{F}^{5} \mathrm{U}$ is the ribo isomer, and the minor product is the arabino isomer [39]. The change in configuration at $\mathrm{C}^{\prime}$ requires deprotonation to form a glycal intermediate, followed by reprotonation from the "top" and "bottom" face to afford the ribo and arabino products. The deprotonation at $\mathrm{C}^{\prime}$ can be achieved by the conserved Asp or $\mathrm{O}^{2}$ of the pentose ring; however, since $\mathrm{O}^{2}$ seem to be unable to access the "bottom" face of the glycal intermediate, the proton from $\mathrm{O}^{2}$ then must migrate to the conserved Asp to reprotonate the glycal intermediate from the "bottom" face to generate the arabino product. Cocrystal structures show that the $\mathrm{O}^{2}$ is located right above $\mathrm{C}^{\prime}$ of the glycal intermediate where it can possibly act as a base to deprotonate $\mathrm{C} 2^{\prime}$ [41].

In this chapter, the isomerized $U$ is replaced by 4 -thiouridine $\left(\mathrm{s}^{4} \mathrm{U}\right)$ in order to test if $\mathrm{O}^{2}$ is a general base of the glycal mechanism. Some bacteria have $\mathrm{s}^{4} \mathrm{U}$ at position 8 in tRNA, and it serves as a sensor for near-UV light [49]. The lower $\mathrm{p} K_{\mathrm{a}}$ for $\mathrm{s}^{4} \mathrm{U}$ (8.2) relative to $\mathrm{U}(9.2)$ reflects the greater stability of the anion of 4-thiouracil than the anion of uracil; hence the leaving group is better for $s^{4} U$ than $U$, which increase the rates of reaction. However, the lower $\mathrm{p} K_{\mathrm{a}}$ for $\mathrm{s}^{4} \mathrm{U}$ also makes the 4-thiouracil(ate) a weaker base than uracil(ate), thus making it harder to deprotonate $\mathrm{C}^{\prime}$ and slowing the rate of reaction. 
Because the overall rate of the reaction depends on leaving group departure and deprotonation of $\mathrm{C}^{\prime}$, a slower rate of reaction will indicate $\mathrm{O}^{2}$ is a general base since leaving group departure should be faster with $\mathrm{s}^{4} \mathrm{U}$. As an essential first step, RNA containing s ${ }^{4} U$ needs to be verified as a good substrate for $\Psi$ synthase. Therefore, assays

of $s^{4} U$ with TruB and RluA were performed. Both intact and digested of [ $\left.{ }^{4} U\right] T S L$ and $\left[\mathrm{s}^{4} \mathrm{U}\right] \mathrm{ASL}$ were analyzed by reverse-phase HPLC after incubation with TruB and RluA, respectively.

\subsection{Experimental}

\subsubsection{Materials}

Competent BLR(DE3) pLysS E. coli cells were purchased from Novagen (Madison, WI). A CLIPEUS $\mathrm{C}_{8} 5-\mu \mathrm{m}$ column $(250 \times 4.6 \mathrm{~mm})$ was purchased from Higgins Analytical, Inc. (Mountain View, CA), and a Zorbax analytical SB-C 18 5- $\mu \mathrm{m}$ column $(50 \times 4.6 \mathrm{~mm})$ was purchased from Agilent (Santa Clara, CA). Ni-NTA superflow resin and QIAprep Spin Mini prep kits were purchased from Qiagen (Chatsworth, CA). S1 nuclease and calf intestinal alkaline phosphatase were purchased from Promega (Madison, WI). Oligonucleotide $\left[\mathrm{s}^{4} \mathrm{U}\right] \mathrm{ASL}\left(5^{\prime}\right.$-GGGGAs ${ }^{4}$ UUGAAAAUCCCC-3') and $\left[\mathrm{s}^{4} \mathrm{U}\right] \mathrm{TSL}\left(5^{\prime}-\mathrm{CUGUGUs}{ }^{4} \mathrm{UCGAUCCACAG}^{\prime} 3^{\prime}\right)$ were purchased from Thermofisher Dharmacon (Lafayette, CO). Ultra-pure deionized water was obtained using a Millipore ${ }^{\circledR}$ Milli-Q integral system (Billerica, MA) equipped with a $0.2 \mu \mathrm{m}$ filter. Laemmli buffer $(2 \times)$ was $120 \mathrm{mM}$ Tris $\bullet \mathrm{HCl}$ buffer, $\mathrm{pH}$ 6.8, containing SDS (4\%, w/v), glycerol $(20 \%, \mathrm{v} / \mathrm{v})$, and bromophenol blue $(0.02 \%, \mathrm{w} / \mathrm{v})$. RNA loading dye $(2 \times)$ was $95 \%$ aqueous formamide containing bromophenol blue $(0.025 \%$, w/v), xylene cyanol $(0.025 \%, \mathrm{w} / \mathrm{v})$, and EDTA $(0.5 \mathrm{mM})$. 


\subsubsection{Overexpression and purification of wild-type RluA and TruB}

Overexpression and purification of wild-type RluA. An overnight culture of

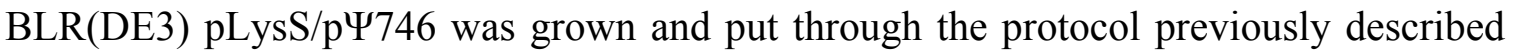
for overexpression and purification of Y96F RluA (Chapter 2.2.2).

Overexpression and purification of wild-type TruB. Purified, RNase-free TruB was generously provided by A. Gibbs (University of Louisville).

\subsubsection{Deprotection and Purification of 2'-ACE RNA Oligonucleotides}

ASL containing 4-thiouridine ([ $\left.\left.\mathrm{s}^{4} \mathrm{U}\right] \mathrm{ASL}\right)\left(5^{\prime}-\mathrm{GGGGAs}^{4} \mathrm{UUGAAAAUCCCC}-3^{\prime}\right)$ and TSL containing 4-thiouridine ([ $\left.\left.\mathrm{s}^{4} \mathrm{U}\right] \mathrm{TSL}\right)$ (5'-CUGUGUs ${ }^{4}{ }^{4}$ CGAUCCACAG- ${ }^{\prime}$ ) were purchased from Thermofisher Dharmacon (Lafayette, CO). The $\left[\mathrm{s}^{4} \mathrm{U}\right] \mathrm{ASL}$ and $\left[\mathrm{s}^{4} \mathrm{U}\right] \mathrm{TSL}$ were deprotected and purified as described above (Chapter 2.2.3). The final $\left[\mathrm{s}^{4} \mathrm{U}\right] \mathrm{ASL}$ and $\left[\mathrm{s}^{4} \mathrm{U}\right] \mathrm{TSL}$ concentration were determined using $\mathrm{A}_{260}$ and extinction coefficients $\left(170,500 \mathrm{M}^{-1} \mathrm{~cm}^{-1}\right.$ and $162,800 \mathrm{M}^{-1} \mathrm{~cm}^{-1}$, respectively) provided by Dharmacon.

\subsubsection{Assay of RluA and ASL containing 4-thiouridine}

Reaction of $\left[\mathbf{s}^{4} \boldsymbol{U}\right] \boldsymbol{A S \boldsymbol { L }}$. The reaction mixture $(200 \mu \mathrm{L})$ was $50 \mathrm{mM}$ HEPES buffer, pH 7.5, containing sodium chloride $(175 \mathrm{mM})$, DTT (5 mM), EDTA (1mM), RNase inhibitor (30 units), and $\left[\mathrm{s}^{4} \mathrm{U}\right] \mathrm{ASL}(10 \mu \mathrm{M})$. After pre-equilibration at $37^{\circ} \mathrm{C}$, the reaction was initiated by the addition of RluA (to $10 \mu \mathrm{M}$ ). Aliquots ( $75 \mu \mathrm{L}$ ) were removed after $3 \mathrm{~h}$ and immediately added to quench solution $(25 \mu \mathrm{L})$, which was $0.5 \mathrm{M}$ sodium phosphate buffer, $\mathrm{pH} 7.5$, containing sodium chloride $(0.5 \mathrm{M})$, then heated at $97{ }^{\circ} \mathrm{C}$ for 10 min. The quenched aliquots were passed over G-25 spin columns that had been preequilibrated with $125 \mathrm{mM}$ sodium phosphate buffer, $\mathrm{pH} 7.5$, containing sodium chloride 
(125 mM), then passed through a $0.2 \mu \mathrm{m}$ filter before being analyzed by reverse-phase HPLC as described for intact ASL (Chapter 2.2.4).

Digestion of $\left[\boldsymbol{s}^{4} \boldsymbol{U}\right] \boldsymbol{A S L}$. To confirm the formation of product, $\left[\mathrm{s}^{4} \mathrm{U}\right] \mathrm{ASL}$ was digested after incubation with RluA. Aliquots $(100 \mu \mathrm{L})$ were removed after $3 \mathrm{~h}$ and immediately heated at $97{ }^{\circ} \mathrm{C}$ for $10 \mathrm{~min}$. The aliquot was spun for $10 \mathrm{~min}$ at $14,000 \mathrm{~g}$ to pellet denatured protein, and the supernatant was transferred to a fresh tube and diluted into $50 \mathrm{mM}$ sodium acetate buffer $(100 \mu \mathrm{L}), \mathrm{pH} 4.5$, containing sodium chloride $(280 \mathrm{mM})$ and zinc chloride $(4.5 \mathrm{mM}) . \mathrm{S} 1$ nuclease (100 units) was added; after $1 \mathrm{~h}$ at $37{ }^{\circ} \mathrm{C}$, the digestion mixture was incubated at $100{ }^{\circ} \mathrm{C}$ for $5 \mathrm{~min}$ and then cooled on ice. Additional S1 nuclease (100 units) and alkaline phosphatase (5 units) were added, and the digestion mixture was incubated for an additional $3 \mathrm{~h}$ at $37^{\circ} \mathrm{C}$, then passed through a $0.2 \mu \mathrm{m}$ filter and analyzed by reverse phase HPLC as described for intact ASL (Chapter 2.2.4).

\subsubsection{Assay of TruB and TSL containing 4-thiouridine}

Reaction of $\left[\boldsymbol{s}^{4} \boldsymbol{U}\right.$ JTSL. The reaction mixture $(200 \mu \mathrm{L})$ was $50 \mathrm{mM}$ HEPES buffer, pH 7.5, containing ammonium chloride $(100 \mathrm{mM})$ and EDTA $(0.1 \mathrm{mM})$, RNase inhibitor (30 units), and $\left[\mathrm{s}^{4} \mathrm{U}\right] \mathrm{TSL}(10 \mu \mathrm{M})$. After pre-equilibration at $37{ }^{\circ} \mathrm{C}$, the reaction was initiated by the addition of TruB (to $10 \mu \mathrm{M}$ ) and incubated for $3 \mathrm{~h}$. The analysis followed the protocol as described for the reaction of ASL (Chapter 2.2.4).

Digestion of $\left[\boldsymbol{s}^{4} \boldsymbol{U}\right.$ TSSL. To confirm the formation of product, the digestion of $\left[\mathrm{s}^{4} \mathrm{U}\right] \mathrm{TSL}$ after incubation with TruB was accomplished by the same method described previously for the digestion ASL (Chapter 2.2.4). 


\subsection{Results}

\subsubsection{Assay of RluA and ASL containing 4-thiouridine}

In order to determine if $\left[\mathrm{s}^{4} \mathrm{U}\right] \mathrm{ASL}$ is modified by RluA, $\left[\mathrm{s}^{4} \mathrm{U}\right] \mathrm{ASL}(10 \mu \mathrm{M})$ was incubated with RluA $(10 \mu \mathrm{M})$ at $37^{\circ} \mathrm{C}$ for $3 \mathrm{~h}$ and analyzed by reverse-phase HPLC. The HPLC analysis revealed a shift to later retention time after incubation with RluA (Figure 3.1).

To ensure that the difference in chromatographic behavior of $\left[\mathrm{s}^{4} \mathrm{U}\right] \mathrm{ASL}$ after incubation with RluA arose from alteration of the $\mathrm{s}^{4} \mathrm{U},\left[\mathrm{s}^{4} \mathrm{U}\right] \mathrm{ASL}$ was digested to free nucleosides before and after incubation with RluA and the products were analyzed by reverse-phase HPLC. With detection at $260 \mathrm{~nm}, \mathrm{C}, \mathrm{U}, \mathrm{G}, \mathrm{s}^{4} \mathrm{U}, \mathrm{A}$ were observed with the $\mathrm{s}^{4} \mathrm{U}$ peak greatly diminished, and a new peak (10 min) appeared after reaction. With detection at $330 \mathrm{~nm}, \mathrm{~s}^{4} \mathrm{U}(16.5 \mathrm{~min})$ appeared before incubation with RluA, but the $\mathrm{s}^{4} \mathrm{U}$ was essentially replaced by four sizable peaks, with the largest product peak (10 min) at the same retention time as the new peak detected at $260 \mathrm{~nm}$. These results show that RluA acts on $\left[\mathrm{s}^{4} \mathrm{U}\right] \mathrm{ASL}$, but the identity of the products needs to be investigated further. 


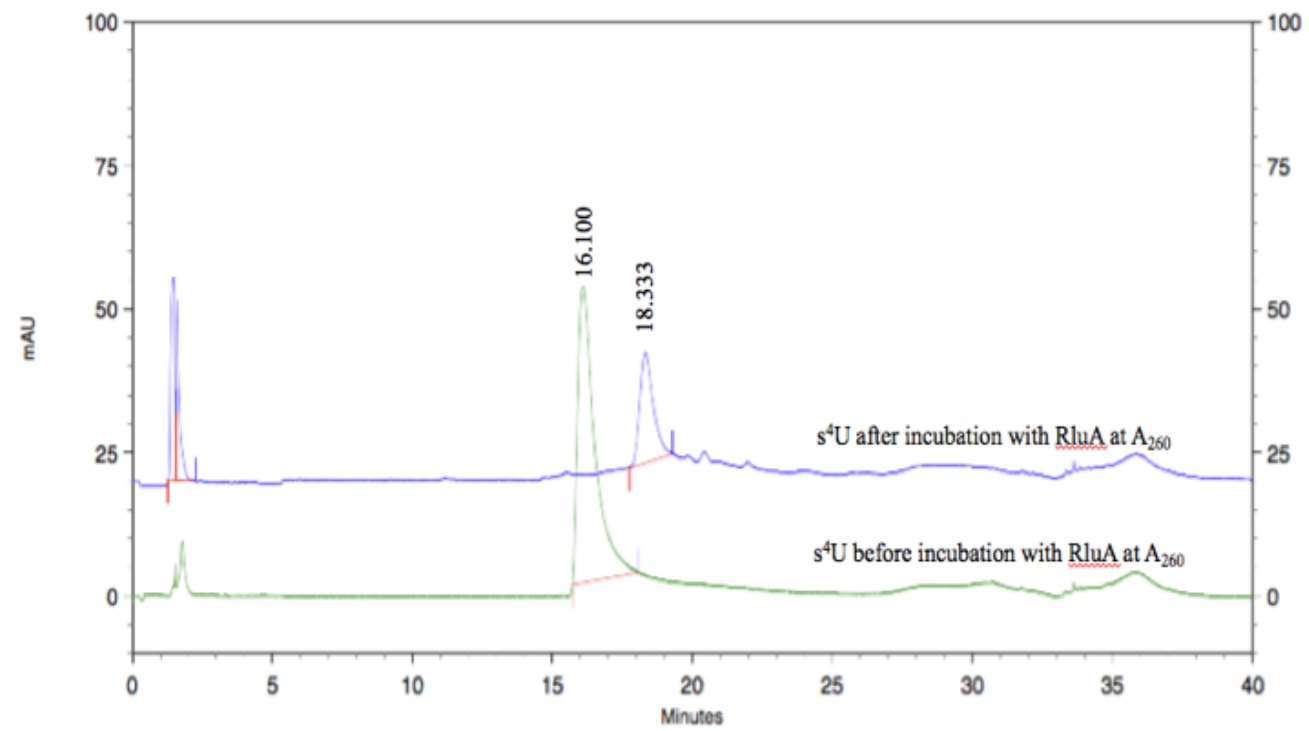

Figure 3.1: HPLC analysis of [ $\left.s^{4} \mathrm{U}\right] \mathrm{ASL}$ before (green) and after (blue) incubation with RluA. The peak at $16.1 \mathrm{~min}$ and $18.3 \mathrm{~min}$ are $\left[\mathrm{s}^{4} \mathrm{U}\right] \mathrm{ASL}$ before and after incubation with WT RluA, respectively.

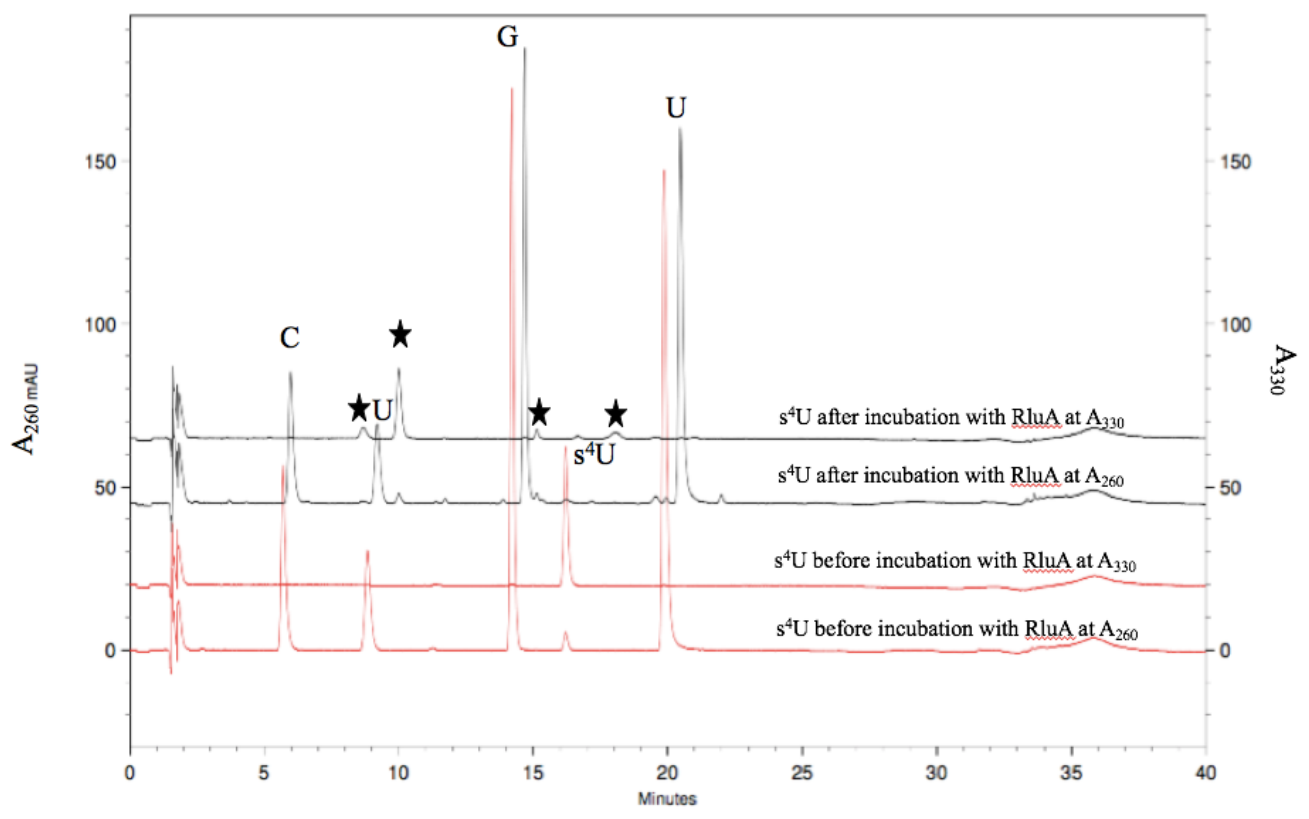

Figure 3.2: HPLC analysis of the nucleosides resulting from digestion of $\left[\mathrm{s}^{4} \mathrm{U}\right] \mathrm{ASL}$ before (red) and after (black) incubation with RluA. The stars indicates the location of the new peaks. 


\subsubsection{Assay of TruB and TSL containing 4-thiouridine}

To investigate further whether results with RluA and $\left[\mathrm{s}^{4} \mathrm{U}\right] \mathrm{ASL}$ are common to another family of $\Psi$ synthases, the same set of reactions were performed with $E$. coli TruB and $\left[s^{4} U\right]$ TSL. HPLC analysis showed that incubation with TruB slightly shifts $\left[\mathrm{s}^{4} \mathrm{U}\right] \mathrm{TSL}$ to a shorter retention time $(18.3 \mathrm{~min})$ compared to unreacted $\left[\mathrm{s}^{4} \mathrm{U}\right] \mathrm{TSL}$ (18.7 min) (Figure 3.4). To make sure that the change in $\left[\mathrm{s}^{4} \mathrm{U}\right] \mathrm{TSL}$ was due to reaction of $\mathrm{s}^{4} \mathrm{U},\left[\mathrm{s}^{4} \mathrm{U}\right] \mathrm{TSL}$ both before and after incubation with TruB was digested to free nucleosides, which were characterized by HPLC. With detection at $260 \mathrm{~nm}, \mathrm{C}, \mathrm{U}, \mathrm{G}, \mathrm{s}^{4} \mathrm{U}$, A were observed after reaction, but the $s^{4} U$ peak was replaced by two new peaks (13 and $19.5 \mathrm{~min})$. With detection at $330 \mathrm{~nm}, \mathrm{~s}^{4} \mathrm{U}(16.5 \mathrm{~min})$ appeared before incubation with TruB but was essentially replaced by four sizable peaks $(8,10,13$, and $19.5 \mathrm{~min})$ after incubation. These results show that TruB acts on $\left[s^{4} U\right] T S L$, but the identity of the products needs to be further investigated. 


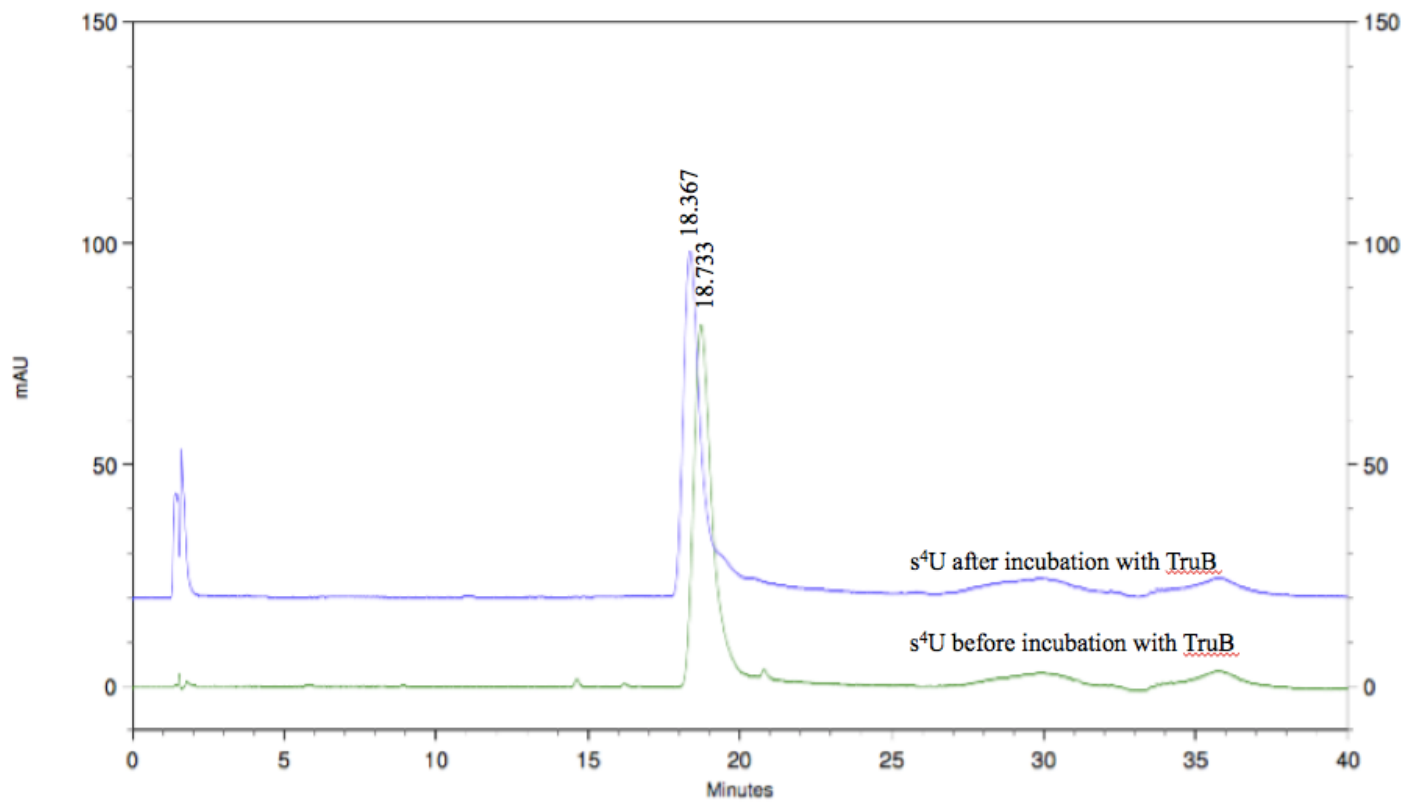

Figure 3.3: HPLC analysis of $\left[\mathrm{s}^{4} \mathrm{U}\right.$ TSL before (green) and after (blue) incubation with TruB. The peak at $18.7 \mathrm{~min}$ is $\left[\mathrm{s}^{4} \mathrm{U}\right]$ TSL before incubation with TruB, and the peak at $18.3 \mathrm{~min}$ is $\left[\mathrm{s}^{4} \mathrm{U}\right] \mathrm{TSL}$ after incubation with TruB.

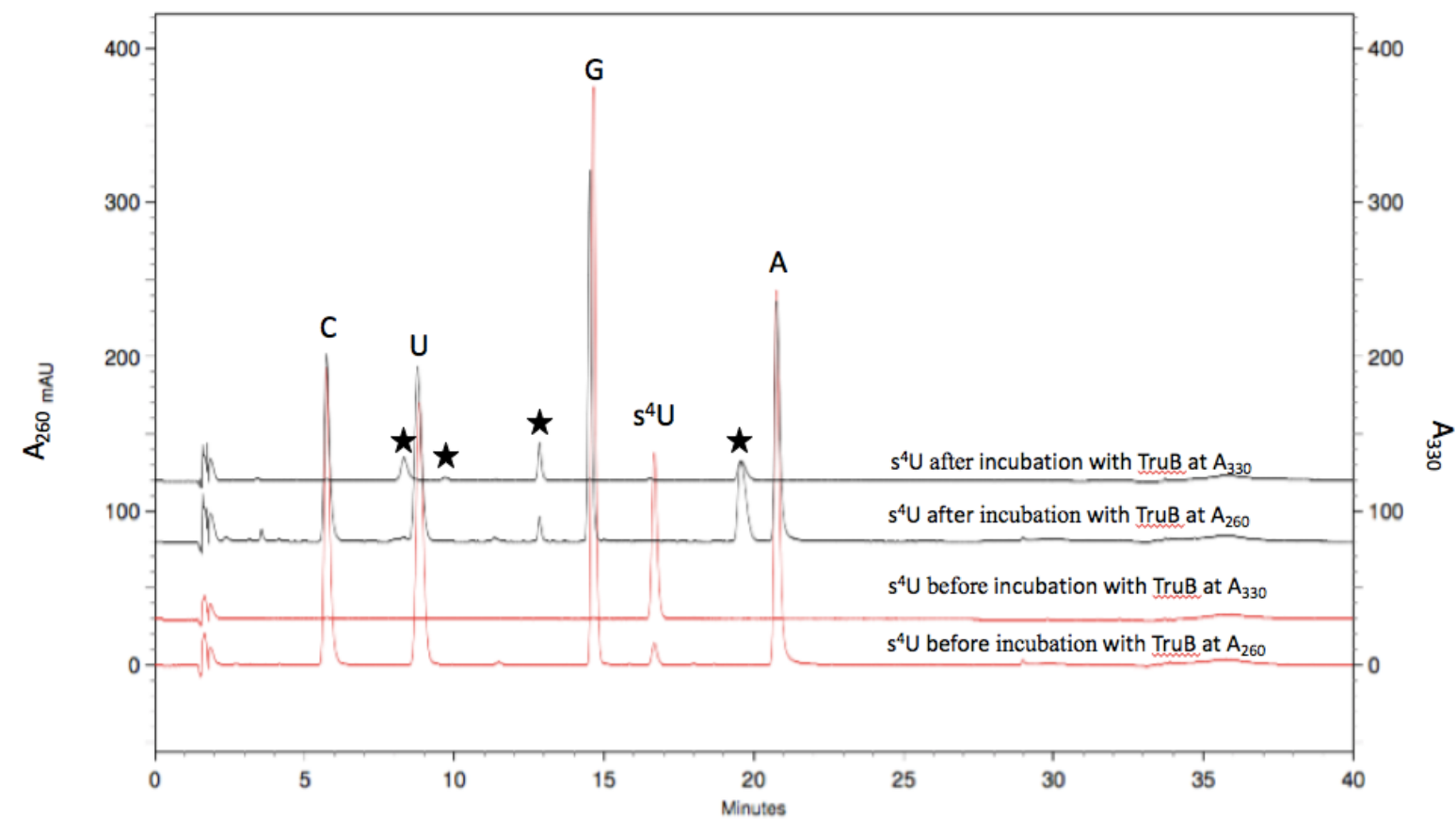

Figure 3.4: HPLC analysis of the nucleosides resulting from digestion of $\left[\mathrm{s}^{4} \mathrm{U}\right] \mathrm{TSL}$ before (red) and after (black) incubation with TruB. The stars indicates the location of the new peaks. 


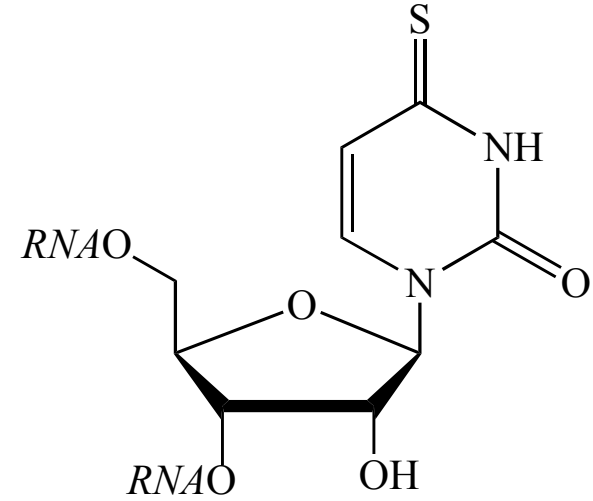

$\mathbf{s}^{4} \mathbf{U}$

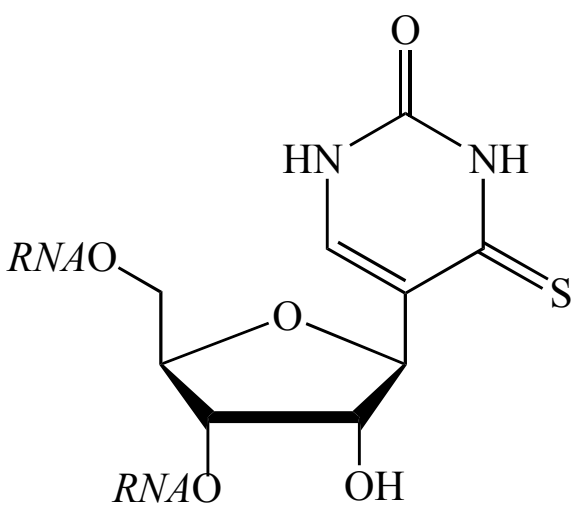

$\mathbf{s}^{4} \Psi$

Figure 3.5: The isomerization of $s^{4} U$ to $s^{4} \Psi$.

A

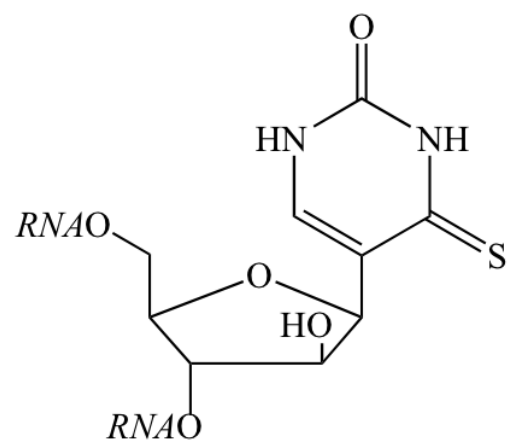

B

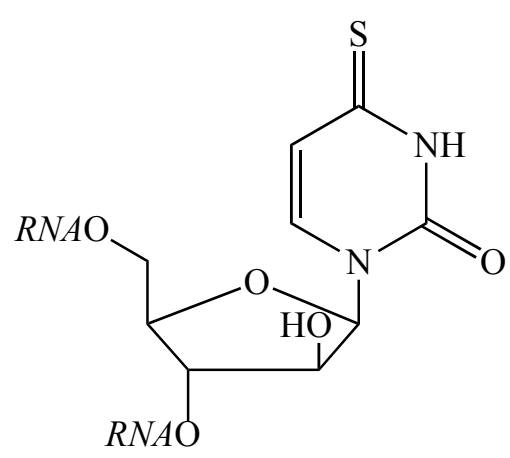

Figure 3.6: A, the arabino-s ${ }^{4} \Psi$ product. B, the arabino-s ${ }^{4} U$ product. 
A

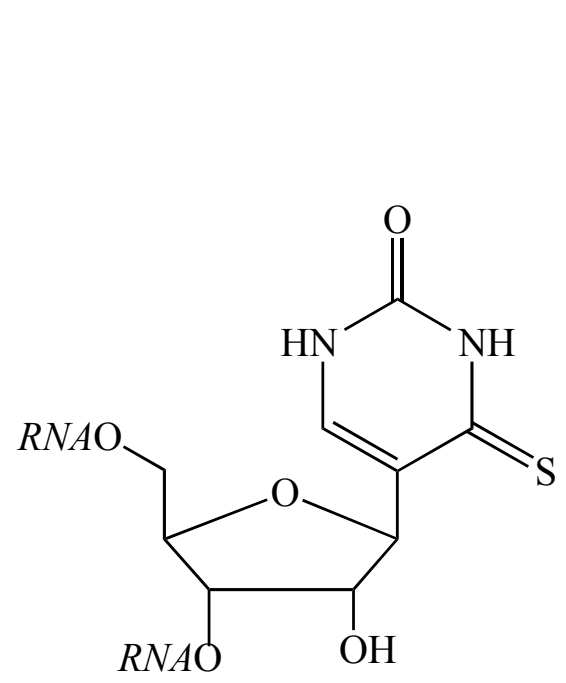

RluA product
B

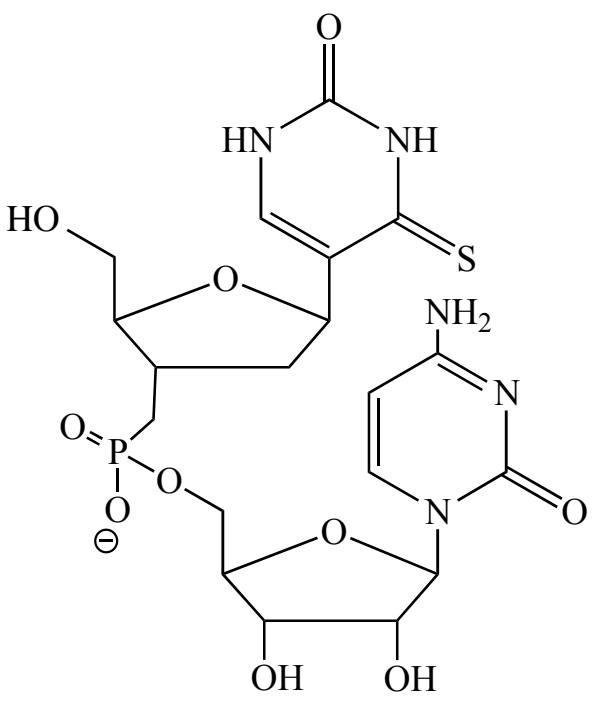

TruB product

Figure 3.7: A, The ribo- $s^{4} \Psi$ product from the action of RluA. B, Dinucleotide product from the action of TruB.
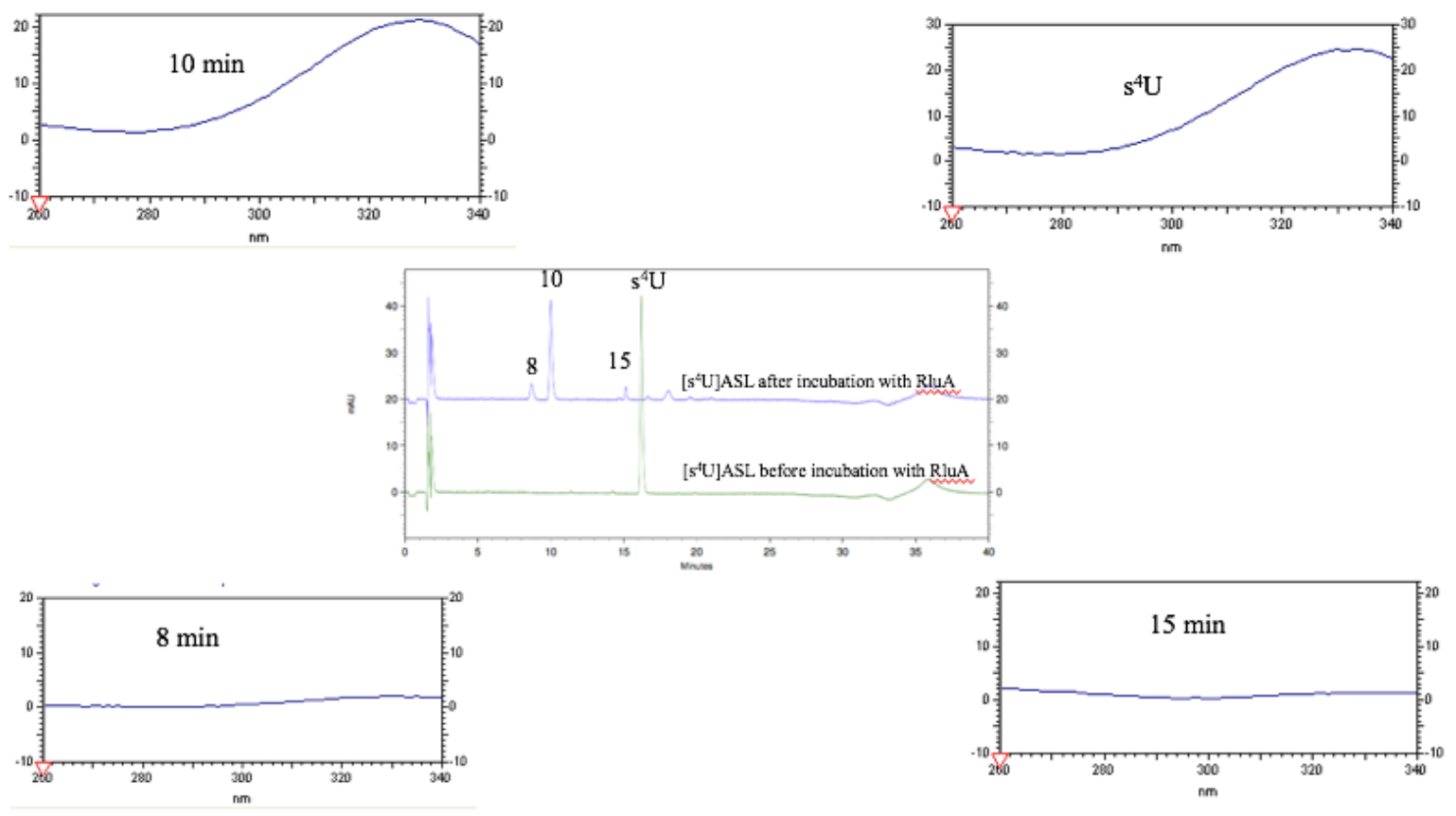

Figure 3.8: The spectra of new peaks from the action of RluA. 

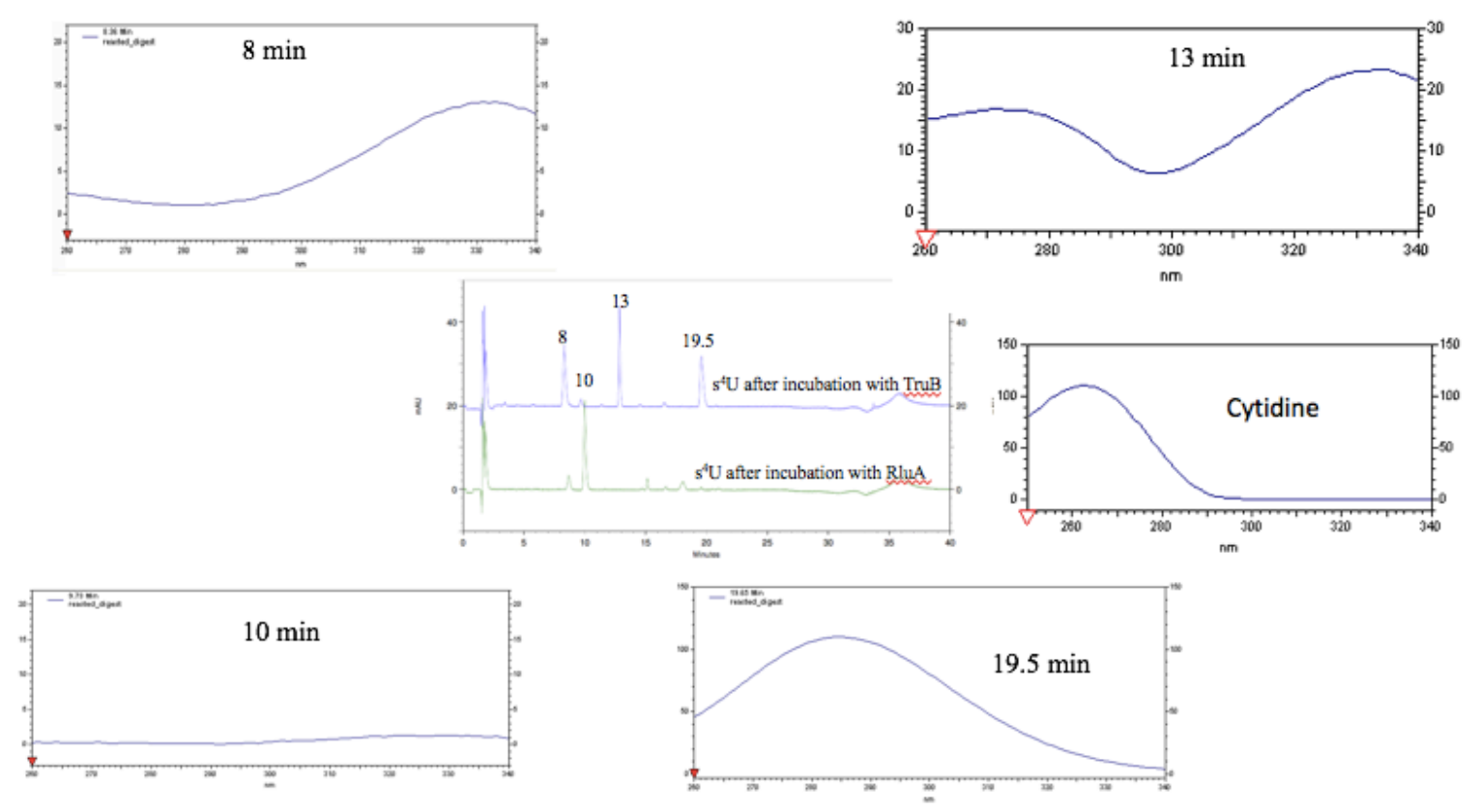

Figure 3.9: The spectra of new peaks from the action of TruB.

\subsection{Discussion}

Studies of the interaction of TruB and RluA with $\left[\mathrm{F}^{5} \mathrm{U}\right] \mathrm{RNA}$ revealed that both enzymes convert $\mathrm{F}^{5} \mathrm{U}$ into two products, and the difference between them is at $\mathrm{C} 2{ }^{\prime}$ of the pentose ring: the major product is the ribo isomer whereas the minor product is the arabino isomer [39]. To explain the arabino product of $\mathrm{F}^{5} \mathrm{U}, \mathrm{C} 2^{\prime}$ must be deprotonated followed by reprotonation from the opposite face. The deprotonation at $\mathrm{C} 2$ ' can be achieved either by the conserved Asp or $\mathrm{O}^{2}$ of uracil. $\mathrm{O}^{2}$ is positioned directly above $\mathrm{C}^{\prime}$, which is a good position to act as base to generate the glycal intermediate [41]. However, $\mathrm{O}^{2}$ seems to be unable to access the "bottom face" of the glycal intermediate, so the proton must migrate from $\mathrm{O}^{2}$ to the conserved Asp in order to reprotonate from the distal face. To determine whether $\mathrm{O}^{2}$ is the general base, the reaction of RNA containing s ${ }^{4} \mathrm{U}$ 
([ $\left.\left.\mathrm{s}^{4} \mathrm{U}\right] \mathrm{RNA}\right)$ in place of $\mathrm{U}$ was used. To ensure that $\left[\mathrm{s}^{4} \mathrm{U}\right] \mathrm{RNA}$ can act as a substrate, assays of TruB and RluA with $\left[\mathrm{s}^{4} \mathrm{U}\right] \mathrm{RNA}$ were performed and analyzed by reverse-phase HPLC. Intact $\left[\mathrm{s}^{4} \mathrm{U}\right] \mathrm{RNA}$ shifted to later and shorter retention times after incubation with RluA and TruB, respectively, and peak integration indicated that all of the $\left[\mathrm{s}^{4} \mathrm{U}\right] \mathrm{RNA}$ reacted. Traces of the digestion products of $\left[\mathrm{s}^{4} \mathrm{U}\right] \mathrm{RNA}$ after incubation with the two enzymes showed the new peaks that absorbed more strongly at $330 \mathrm{~nm}$ than $260 \mathrm{~nm}$. These results indicate that both RluA and TruB act on $\left[s^{4} \mathrm{U}\right] \mathrm{RNA}$, and thus $\left[\mathrm{s}^{4} \mathrm{U}\right] \mathrm{RNA}$ can be handled as a substrate. The product is expected to be 4-thiopseudouridine ( $\mathrm{s}^{4} \Psi$; Figure 3.5).

The action of RluA replaced the $s^{4} U$ peak with four sizable peaks $(8,10,15$, and $18 \mathrm{~min}$ ). Because $\mathrm{s}^{4} \Psi$ is more polar than $\mathrm{s}^{4} \mathrm{U}, \mathrm{s}^{4} \Psi$ should elute earlier in reverse phase HPLC, which agrees with the tentative assignment of the largest product peak (10 min; Figure 3.2) as $\mathrm{s}^{4} \Psi$ (Figure 3.7A). That peak (10 min) also absorbs more strongly at $330 \mathrm{~nm}$ than $260 \mathrm{~nm}$, which is consistent with the assignment (Figure 3.8). The identities of the minor products ( 8 and $15 \mathrm{~min}$; Figure 3.2) are less sure, but based on the precedent of $\left[\mathrm{F}^{5} \mathrm{U}\right] \mathrm{RNA}$ [26], one may be arabino-s $\mathrm{s}^{4} \Psi$ (Figure 3.6A) and the other arabino-s $\mathrm{s}^{4} \mathrm{U}$ (Figure 3.6B). The latter is rationalized because sulfur is larger than oxygen, so the rotation of 4-thiouracil(ate) in the active site may be harder than for uracil(ate), leading $\mathrm{N} 1$ to attack $\mathrm{Cl}^{\prime}$ ' of the glycal intemadiate with reprotonation from "bottom" face.

Similar to the results with RluA, the $s^{4} U$ peak was replaced with four sizable peaks $(8,10,13$, and $19.5 \mathrm{~min})$ after incubation with TruB. The peak at $19.5 \mathrm{~min}$ has an absorbance maximum at $285 \mathrm{~nm}$, so it does not contain a 4-thiouracil chromophore (Figure 3.9). Among the other three peaks 8, 10, 13 min with ratio of 9:1:10, respectively; 
the spectrum of the peak at 13 min shows two peaks with absorbance maxima at $270 \mathrm{~nm}$ and $330 \mathrm{~nm}$ (Figure 3.9), which are characteristic of cytidine and $\mathrm{s}^{4} \mathrm{U}$ and therefore suggests that the $\mathrm{s}^{4} \mathrm{U}$ product at $13 \mathrm{~min}$ formed by the action of $\mathrm{TruB}$ is a dinucleotide of an $\mathrm{s}^{4} \mathrm{U}$ product with the cytidine residue that follows $\mathrm{s}^{4} \mathrm{U}$ in $\left[\mathrm{s}^{4} \mathrm{U}\right] \mathrm{TSL}$ (Figure 3.7B). The peaks at 8 and $10 \mathrm{~min}$ seem to elute at the same retention time as peaks at 8 and $10 \mathrm{~min}$ on the action of RluA. Also, the spectra of the two peaks show they are not dinucleotides (Figure 3.9), thus the peak at 8 may be arabino-s $\mathrm{s}^{4} \Psi$ or arabino-s $\mathrm{s}^{4} \mathrm{U}$, and the peak at $10 \mathrm{~min}$ is tentatively assigned as $\mathrm{s}^{4} \Psi$. To confirm the different products, liquid chromatography-mass spectroscopy can be used since the dinucleotide product have higher molecular mass than mononucleotide. ${ }^{1} \mathrm{H}-\mathrm{NMR}$ can distinguish between arabino$\mathrm{s}^{4} \Psi$ or arabino-s $\mathrm{s}^{4} \mathrm{U}$ and $\mathrm{s}^{4} \Psi$ product.

Once the products are identified, the full kinetic characterization of RluA and TruB with $\left[\mathrm{s}^{4} U\right] R N A$ substrate will be performed in order to compare the difference in rates of the reaction catalyzed by RluA and TruB with natural substrate versus $\left[\mathrm{s}^{4} \mathrm{U}\right] \mathrm{RNA}$. A slower rate with $\left[\mathrm{s}^{4} \mathrm{U}\right] \mathrm{RNA}$ will imply $\mathrm{O}^{2}$ is the general base, but a faster rate will not. 


\section{REFERENCES}

1. Cohn WE: Pseudouridine, a Carbon-Carbon Linked Ribonucleoside in Ribonucleic Acids: Isolation, Structure, and Chemical Characteristics. Journal of Biological Chemistry 1960, 235(5):1488-1498.

2. Rozenski J, Crain PF, McCloskey JA: The RNA Modification Database: 1999 update. Nucleic Acids Research 1999, 27(1):196-197.

3. Charette M, Gray MW: Pseudouridine in RNA: What, Where, How, and Why. IUBMB Life 2000, 49(5):341-351.

4. Carlile TM, Rojas-Duran MF, Zinshteyn B, Shin H, Bartoli KM, Gilbert WV: Pseudouridine profiling reveals regulated mRNA pseudouridylation in yeast and human cells. Nature 2014, 515(7525):143-146.

5. Lane BG, Ofengand J, Gray MW: Pseudouridine and O2-methylated nucleosides. Significance of their selective occurrence in rRNA domains that function in ribosome-catalyzed synthesis of the peptide bonds in proteins. Biochimie 1995, 77(1):7-15.

6. Davis DR: Biophysical and Conformational Properties of Modified Nucleosides in RNA (Nuclear Magnetic Resonance Studies). In: Modification and Editing of $R N A$. American Society of Microbiology; 1998.

7. Davis DR: Stabilization of RNA stacking by pseudouridine. Nucleic Acids Research 1995, 23(24):5020-5026.

8. Auffinger P, Westhof E: Effects of Pseudouridylation on tRNA Hydration and Dynamics: a Theoretical Approach. In: Modification and Editing of RNA. American Society of Microbiology; 1998.

9. Yarian CS, Basti MM, Cain RJ, Ansari G, Guenther RH, Sochacka E, Czerwinska G, Malkiewicz A, Agris PF: Structural and functional roles of the N1- and N3protons of $\Psi$ at tRNA's position 39. Nucleic Acids Research 1999, 27(17):35433549.

10. Raychaudhuri S, Conrad J, Hall BG, Ofengand J: A pseudouridine synthase required for the formation of two universally conserved pseudouridines in ribosomal RNA is essential for normal growth of Escherichia coli. RNA 1998, 4(11):1407-1417.

11. Raychaudhuri S, Niu L, Conrad J, Lane BG, Ofengand J: Functional Effect of Deletion and Mutation of theEscherichia coli Ribosomal RNA and tRNA Pseudouridine Synthase RluA. Journal of Biological Chemistry 1999, 274(27):18880-18886.

12. Conrad J, Niu L, Rudd K, Lane BG, Ofengand J: $16 \mathrm{~S}$ ribosomal RNA pseudouridine synthase RsuA of Escherichia coli: deletion, mutation of the 
conserved Asp102 residue, and sequence comparison among all other pseudouridine synthases. $R N A$ 1999, 5(6):751-763.

13. Lenz HJ, Manno DJ, Danenberg KD, Danenberg PV: Incorporation of 5fluorouracil into U2 and U6 snRNA inhibits mRNA precursor splicing. Journal of Biological Chemistry 1994, 269(50):31962-31968.

14. Luzzatto L, Karadimitris A: Dyskeratosis and ribosomal rebellion. Nature Genetics 1998, 19(1):6-7.

15. Heiss NS, Knight SW, Vulliamy TJ, Klauck SM, Wiemann S, Mason PJ, Poustka A, Dokal I: X-linked dyskeratosis congenita is caused by mutations in a highly conserved gene with putative nucleolar functions. Nature Genetics 1998, 19(1):32-38.

16. Mitchell JR, Wood E, Collins K: A telomerase component is defective in the human disease dyskeratosis congenita. Nature 1999, 402(6761):551-555.

17. Koonin EV: Pseudouridine Synthases: Four Families of Enzymes Containing a Putative Uridine-Binding Motif Also Conserved in dUTPases and dCTP Deaminases. Nucleic Acids Research 1996, 24(12):2411-2415.

18. Gustafsson C, Reid R, Greene PJ, Santi DV: Identification of New RNA Modifying Enzymes by Iterative Genome Search Using Known Modifying Enzymes as Probes. Nucleic Acids Research 1996, 24(19):3756-3762.

19. KAYA Y, OFENGAND J: A novel unanticipated type of pseudouridine synthase with homologs in bacteria, archaea, and eukarya. RNA 2003, 9(6):711-721.

20. Ma X, Zhao X, Yu YT: Pseudouridylation ( $\Psi)$ of U2 snRNA in S.cerevisiae is catalyzed by an RNA-independent mechanism. The EMBO Journal 2003, 22(8):1889.

21. Kammen HO, Marvel CC, Hardy L, Penhoet EE: Purification, structure, and properties of Escherichia coli tRNA pseudouridine synthase I. Journal of Biological Chemistry 1988, 263(5):2255-2263.

22. Nurse K, Wrzesinski J, Bakin A, Lane BG, Ofengand J: Purification, cloning, and properties of the tRNA psi 55 synthase from Escherichia coli. RNA 1995, 1(1):102-112.

23. Wrzesinski J, Nurse K, Bakin A, Lane BG, Ofengand J: A dual-specificity pseudouridine synthase: an Escherichia coli synthase purified and cloned on the basis of its specificity for psi 746 in 23S RNA is also specific for psi 32 in tRNA $^{\text {Phe }}$. RNA 1995, 1(4):437-448.

24. Wrzesinski J, Bakin A, Nurse K, Lane BG, Ofengand J: Purification, cloning, and properties of the 16S RNA pseudouridine 516 synthase from Escherichia coli. Biochemistry 1995, 34(27):8904-8913.

25. Gurha P, Gupta R: Archaeal Pus10 proteins can produce both pseudouridine 54 and 55 in tRNA. RNA (New York, NY) 2008, 14(12):2521-2527.

26. Ramamurthy V, Swann SL, Paulson JL, Spedaliere CJ, Mueller EG: Critical Aspartic Acid Residues in Pseudouridine Synthases. Journal of Biological Chemistry 1999, 274(32):22225-22230.

27. Huang L, Pookanjanatavip M, Gu X, Santi DV: A Conserved Aspartate of tRNA Pseudouridine Synthase Is Essential for Activity and a Probable Nucleophilic Catalyst. Biochemistry 1998, 37(1):344-351. 
28. Hamma T, Ferré-D'Amaré AR: Pseudouridine Synthases. Chemistry \& Biology 2006, 13(11):1125-1135.

29. Hamilton CS, Greco TM, Vizthum CA, Ginter JM, Johnston MV, Mueller EG: Mechanistic Investigations of the Pseudouridine Synthase RluA Using RNA Containing 5-Fluorouridine. Biochemistry 2006, 45(39):12029-12038.

30. Gu X, Yu M, Ivanetich KM, Santi DV: Molecular Recognition of tRNA by tRNA Pseudouridine 55 Synthase. Biochemistry 1998, 37(1):339-343.

31. Longley DB, Harkin DP, Johnston PG: 5-Fluorouracil: mechanisms of action and clinical strategies. Nature Reviews Cancer 2003, 3(5):330-338.

32. Samuelsson T: Interactions of transfer RNA pseudouridine synthases with RNAs substituted with fluorouracil. Nucleic Acids Research 1991, 19(22):6139-6144.

33. Santi DV, McHenry CS, Sommer H: Mechanism of interaction of thymidylate synthetase with 5-fluorodeoxyuridylate. Biochemistry 1974, 13(3):471-481.

34. Gu X, Liu Y, Santi DV: The mechanism of pseudouridine synthase I as deduced from its interaction with 5-fluorouracil-tRNA. Proceedings of the National Academy of Sciences 1999, 96(25):14270-14275.

35. Hoang C, Ferré-D'Amaré AR: Cocrystal Structure of a tRNA $\Psi 55$ Pseudouridine Synthase: Nucleotide Flipping by an RNA-Modifying Enzyme. Cell 2001, 107(7):929-939.

36. Spedaliere CJ, Mueller EG: Not all pseudouridine synthases are potently inhibited by RNA containing 5-fluorouridine. RNA 2004, 10(2):192-199.

37. Spedaliere CJ, Ginter JM, Johnston MV, Mueller EG: The Pseudouridine Synthases: Revisiting a Mechanism That Seemed Settled. Journal of the American Chemical Society 2004, 126(40):12758-12759.

38. McDonald MK, Miracco EJ, Chen J, Xie Y, Mueller EG: The Handling of the Mechanistic Probe 5-Fluorouridine by the Pseudouridine Synthase TruA and Its Consistency with the Handling of the Same Probe by the Pseudouridine Synthases TruB and RluA. Biochemistry 2011, 50(3):426-436.

39. Miracco EJ, Mueller EG: The Products of 5-Fluorouridine by the Action of the Pseudouridine Synthase TruB Disfavor One Mechanism and Suggest Another. Journal of the American Chemical Society 2011, 133(31):11826-11829.

40. Veerareddygari GR, Singh SK, Mueller EG: The Pseudouridine Synthases Proceed through a Glycal Intermediate. Journal of the American Chemical Society 2016, 138(25):7852-7855.

41. Paul D, O'Leary SE, Rajashankar K, Bu W, Toms A, Settembre EC, Sanders JM, Begley TP, Ealick SE: Glycal Formation in Crystals of Uridine Phosphorylase. Biochemistry 2010, 49(16):3499-3509.

42. Kumar RK, Davis DR: Synthesis and Studies on the Effect of 2-Thiouridine and 4-Thiouridine on Sugar Conformation and RNA Duplex Stability. Nucleic Acids Research 1997, 25(6):1272-1280.

43. Romby P, Carbon P, Westhof E, Ehresmann C, Ebel J-P, Ehresmann B, Giegé R: Importance of Conserved Residues for the Conformation of the T-Loop in tRNAs. Journal of Biomolecular Structure and Dynamics 1987, 5(3):669-687.

44. Thomas G, Favre A: 4-Thiouridine Triggers Both Growth Delay Induced by Near-Ultraviolet Light and Photoprotection. European Journal of Biochemistry 1980, 113(1):67-74. 
45. Phannachet K, Elias Y, Huang RH: Dissecting the Roles of a Strictly Conserved Tyrosine in Substrate Recognition and Catalysis by Pseudouridine 55 Synthase. Biochemistry 2005, 44(47):15488-15494.

46. Hamilton CS, Spedaliere CJ, Ginter JM, Johnston MV, Mueller EG: The roles of the essential Asp-48 and highly conserved His-43 elucidated by the $\mathrm{pH}$ dependence of the pseudouridine synthase TruB. Archives of Biochemistry and Biophysics 2005, 433(1):322-334.

47. Czudnochowski N, Ashley GW, Santi DV, Alian A, Finer-Moore J, Stroud RM: The mechanism of pseudouridine synthases from a covalent complex with RNA, and alternate specificity for U2605 versus U2604 between close homologs. Nucleic Acids Research 2014, 42(3):2037-2048.

48. Mueller EG: Chips off the old block. Nature Structural Biology 2002, 9(5):320.

49. Grosjean H, Motorin Y, Morin A: RNA-Modifying and RNA-Editing Enzymes: Methods for Their Identification. In: Modification and Editing of RNA. American Society of Microbiology; 1998. 


\title{
CURRICULUM VITAE
}

\author{
Uyen Duong
}

\section{EDUCATION}

M.S. in Chemistry, Anticipated Graduation Date: August, 2017

Thesis: Mechanistic investigations of Pseudouridine synthases TruB and RluA with RNA containing 5-Fluorouridine and 4-Thiouridine

University of Louisville (2015-Present)

Louisville, KY.

\section{M.S. in Polymer Science \& Engineering}

Thesis: Synthesis and SAR of thiazolidinedione as a novel class of

algicides against harmful algal species

University of Chosun (2008-2010)

Gwangju, Korea

B.S. in Chemistry

Vietnam National University (2004-2008)

Ha Noi, Viet Nam

WORK EXPERIENCE

Research assistant/Teaching assistant

Department of Chemistry, University of Louisville (Jan, 2015-present) 
- Expertise in the fields of enzyme assay, enzyme kinetics, protein overexpression, purification and characterization using conventional biochemistry methods

- Two years of experience in handling instruments such as IR, NMR, HPLC, FPLC, UV-Vis. Efficient in troubles shooting HPLC, FPLC instrument problems

- Two years teaching experience as teaching assistant for Chem343 (Organic 1), Chem344 (Organic 2)

\section{Research assistant}

Department of Polymer Science \& Engineering, Chosun University (Sep. 2008 - Jul. 2008)

- Two years of experience in organic synthesis, and purification of organic compounds

- Ability to work in various chromatographic techniques such as thin-layer chromatography, gas-chromatography, ion exchange, affinity

\section{Research assistant}

Organic Synthesis Laboratory, Department of Chemistry, Vietnam

National University (Jul. 2006 - Jun. 2008)

\section{PUBLICATIONS}


4) Y.-M. Kim, Y. Wu, U. T. Duong, S.-G. Jung, S. W. Kim, H. Cho, E. S. Jin. Algicidal Activity of Thiazolidinedione Derivatives Against Harmful Algal Blooming Species. Mar Biotechnol 2012, 14 (3), 312-322

3) Y.-M. Kim, Y. Wu, U. T. Duong, G. S. Ghodake, S. W. Kim, E. S. Jin, H. Cho. Thiazolidinediones as a Novel Class of Algicides Against Red Tide Harmful Algal Species. Appl Biochem Biotechnol 2010, 162, 2273-2283

2) Y. Wu, U. T. Duong, H. Cho. Synthesis and Evaluation of Novel 15Hydroxyprostaglandin Dehydrogenase Inhibitors. Proceedings of Spring International Convention. May 2009, Daejeon, Korea

1) Nguyen Dinh Trieu, Duong Thi Uyen, Hoang Thi Ly, Pham Thi Ngoc Ha, Le Thi Minh Hang. Synthesis and mass spectroscopy of some derivatives of 1Arylterazoles. The 5th national Conference of Science and Organic Chemical Technology, 257-262, 2007, Hanoi, Vietnam 